\title{
A critical crosscatalytic relationship determines the outcome of competition in a replicator network
}

\author{
Tamara Kosikova and Douglas Philp* \\ School of Chemistry and EaStCHEM, University of St Andrews, North Haugh, \\ St Andrews, Fife KY16 9ST, United Kingdom
}

*Corresponding author e-mail: d.philp@st-andrews.ac.uk

ORCID ID: TK: orcid.org/0000-0001-7886-9660

DP: orcid.org/0000-0002-9198-4302 


\begin{abstract}
A network of two synthetic replicators exhibits a critical unidirectional crosscatalytic relationship that directs competing replication processes. In this network, nitrone $\mathbf{N}$ bearing a 6-methylamidopyridine recognition site can participate in two 1,3-dipolar cycloaddition reactions with two maleimides that differ in the relative position of their carboxylic acid recognition site - either para $\left(\mathbf{M}^{\mathbf{p}}\right)$ or meta $\left(\mathbf{M}^{\mathbf{m}}\right)$ relative to the maleimide ring. These two cycloaddition reactions create replicators trans- $\mathbf{T}^{\mathbf{p}}$ and trans$\mathbf{T}^{\mathbf{m}}$. In isolation, trans $-\mathbf{T}^{\mathbf{p}}$ templates its own formation with an efficiency that is markedly greater than that of trans $-\mathbf{T}^{\mathbf{m}}$. Kinetic fitting and simulations reveal that this efficiency arises from a higher template-mediated rate constant for the cycloaddition and lower stability of the trans-T $\mathbf{T}^{\mathbf{p}}$ template duplex, compared to trans $-\mathbf{T}^{\mathbf{m}}$. By contrast, in a situation where $\mathbf{M}^{\mathbf{p}}$ and $\mathbf{M}^{\mathbf{m}}$ compete for a limited quantity of $\mathbf{N}$, the normally less efficient trans- $\mathbf{T}^{\mathbf{m}}$ outcompetes trans- $\mathbf{T}^{\mathbf{p}}$. Through a series of comprehensive kinetic ${ }^{19} \mathrm{~F}\left\{{ }^{1} \mathrm{H}\right\}$ NMR spectroscopy experiments, this system-level outcome is traced to a critical crosscatalytic pathway, whereby the presence of trans- $\mathbf{T}^{\mathbf{p}}$ templates the formation of trans$\mathbf{T}^{\mathbf{m}}$, but not vice versa. Replicator trans- $\mathbf{T}^{\mathbf{m}}$ also reduces the efficiency of its competitor trans- $\mathbf{T}^{\mathbf{p}}$ by sequestering trans- $\mathbf{T}^{\mathbf{p}}$ in a heteroduplex that is more stable than homoduplex $\left[\mathbf{T}^{\mathbf{p}} \cdot \mathbf{T}^{\mathbf{p}}\right]$. The addition of different templates as instructions reveals that, while the outcome of competition between replicators can be altered selectively, it is limited by the reaction environment employed. These results represent a conceptual and practical framework for the examination of selectivity in replication networks operating outside well-stirred batch reactor conditions.
\end{abstract}




\section{Introduction}

Networks are the building blocks of the world around us, and their inherent interconnectedness ${ }^{1}$ often exerts an influence over our everyday lives that can be challenging to predict. The all-pervasive presence of networks in nature ${ }^{2}$ is reflected in the number of disciplines currently engaged ${ }^{1 \mathrm{c}, 3}$ in the study of complex systems ${ }^{3 a, 4}$ and the properties that emerge through the interactions of their components. Chemistry experienced a paradigm shift around twenty years ago as it moved away from the study of molecular matter in isolation and, instead, began to embrace the notion of complexity and networks. By embracing the nascent field ${ }^{5}$ of systems chemistry, bottom-up approaches for the design, development, and investigation of synthetic chemical models for complex systems have started to appear. A phenomenon of particular interest within the field of systems chemistry is replication. In the context of complex systems, synthetic replicators present a unique opportunity to study these processes using networks constructed from molecules with well-defined structures and with catalytic and recognition properties that can be probed and characterized in detail experimentally. The developments in the field of systems chemistry to date have produced a remarkable variety of replicating systems based on oligonucleotides, ${ }^{6}$ peptides, ${ }^{7}$ and small synthetic molecules, ${ }^{8}$ highlighting and demonstrating that the ability to replicate is not exclusive to biological systems based on nucleic acids and equipped with extensive enzymatic machinery. In addition to self-replication, these systems were shown to express a number of system-level properties such as error-correction, ${ }^{9}$ stereo-specific replication, ${ }^{10}$ and Boolean logic. ${ }^{11}$ Peptide-based replicating systems have, in particular, achieved a significant level of sophistication, examining networks ${ }^{9,10,11 c, 12}$ comprising more than a single replicator-a feature significantly less well explored in replicating systems based on oligonucleotides ${ }^{13}$ and small-organic molecules. ${ }^{14}$ Although the requirements for the operation of minimal self-replicating systems in isolation have been established ${ }^{15}$ firmly, the processes in complex networks in the real world do not operate in isolation. For this reason, in this work, we build on our experience in developing selfreplicating systems based on small organic molecules ${ }^{8 \mathrm{a}, 8 \mathrm{c}, 8 \mathrm{~d}, 8 \mathrm{f}, 8 \mathrm{~g}, 14 \mathrm{a}-\mathrm{c}}$ to design and analyze a network of two replicators, connected directly through a shared building block. This network presents a model system that allows us to study how reaction and recognition-mediated processes impact and govern the preference, i.e., the selectivity, of the network for one replicator over another. 


\section{Design and methodology}

In order to create a minimal self-replicating system, two components, bearing complementary recognition sites, must be connected together by one or more covalent bonds to afford a template that can act as a specific autocatalyst for its own formation. Once formed, this autocatalytic template can pre-organize the building blocks required for its formation in a ternary complex co-conformation that renders their reaction pseudointramolecular. The bond-forming step produces a template dimer, or duplex, which exist in equilibrium with the catalytically active monomeric template.

Here, a network of two replicators is constructed from two maleimides, $\mathbf{M}^{\mathbf{p}}$ and $\mathbf{M}^{\mathbf{m}}$, and a single nitrone $\mathbf{N}^{\left[\text {Ref. }{ }^{14 c]}\right.}$ (Figure 1a, Building blocks). The main distinguishing feature of these two maleimides and the replicators ${ }^{16} \mathbf{T}^{\mathbf{p}[\text { Ref. 14c] }}$ and $\mathbf{T}^{\mathbf{m}}$ (Figure 1a, Replicators) arising from their 1,3dipolar cycloaddition reactions with $\mathbf{N}$, is in the location of the carboxylic acid recognition site on the maleimide component (Figure 1). In particular, $\mathbf{M}^{\mathbf{p}}$ integrates ${ }^{8 \mathrm{a}, 8 \mathrm{c}, 14 \mathrm{a}-\mathrm{c}}$ a phenylacetic acid in position para relative to the maleimide ring, while $\mathbf{M}^{\mathbf{m}}$ incorporates a benzoic acid functionality, in position meta with respect to the maleimide ring. For this reason, we use superscript labels $\mathrm{p}$ and $\mathrm{m}$ to represent the para and meta positions of the carboxylic acid recognition site in maleimides (M) and templates (T) throughout this work. Initially, these two templates are formed via slow, template-independent bimolecular pathways (Figure 1c), typically furnishing two diastereoisomeric products, labeled ${ }^{16}$ trans and cis, in a 3:1 ratio in the absence effects originating from molecular recognition. Once the quantity of template formed is sufficient to allow its association with the unreacted components in a catalytically active ternary complex, $\left[\mathbf{N} \cdot \mathbf{M}^{\mathrm{p}} \cdot \mathbf{T}^{\mathrm{p}}\right]$ or $\left[\mathbf{N} \cdot \mathbf{M}^{\mathrm{m}} \cdot \mathbf{T}^{\mathrm{m}}\right]$ (Figure 1b), the template formation proceeds with significant acceleration via the autocatalytic cycle. The ability of a template to initiate an autocatalytic cycle depends on the strength of the non-covalent recognition-mediated processes (Figure 1d) that govern the recognition between the network components. For example, a replicator with a stronger ${ }^{17}$ recognition process would typically require a lower template concentration to enable selfreplication to proceed.

Replicators $\mathbf{T}^{\mathbf{p}}$ and $\mathbf{T}^{\mathbf{m}}$ possess a recognition unit complementary to the carboxylic acid, namely, a 6-methyl-2-amidopyridine ring that is originally associated with nitrone $\mathbf{N}$ (Figure 1a). The relative positions and identities of recognition sites are conserved in the replicator templates. We envisaged that the slight differences in the type and location of the carboxylic acid recognition elements in each system would produce a reaction network of two replicators, referred to as the $\mathbf{T}^{\mathbf{p}}-\mathbf{T}^{\mathbf{m}}$ network, with the potential for crosscatalytic behavior. Hence, reaction of the three individual components together allows the formation of a network where both templates can form simultaneously (Figure 1b) through two auto- and two crosscatalytic pathways. The ability of the templates $\mathbf{T}^{\mathbf{p}}$ and $\mathbf{T}^{\mathbf{m}}$ 
to act as either auto- or crosscatalytic templates allows the network to be instructed to form one replicator over another by the addition of preformed $\mathbf{T}^{\mathbf{p}}$ or $\mathbf{T}^{\mathbf{m}}$. Ultimately, the ability of our replicators to compete for the shared nitrone building block will depend on their ability to take part in these autoand crosscatalytic cycles and for this reason, we wished to undertake a comprehensive kinetic analysis of this small network constructed from two self-replicators to develop an understanding of how structural changes alter the selectivity for one replicator over another and their role in driving systemlevel behavior.
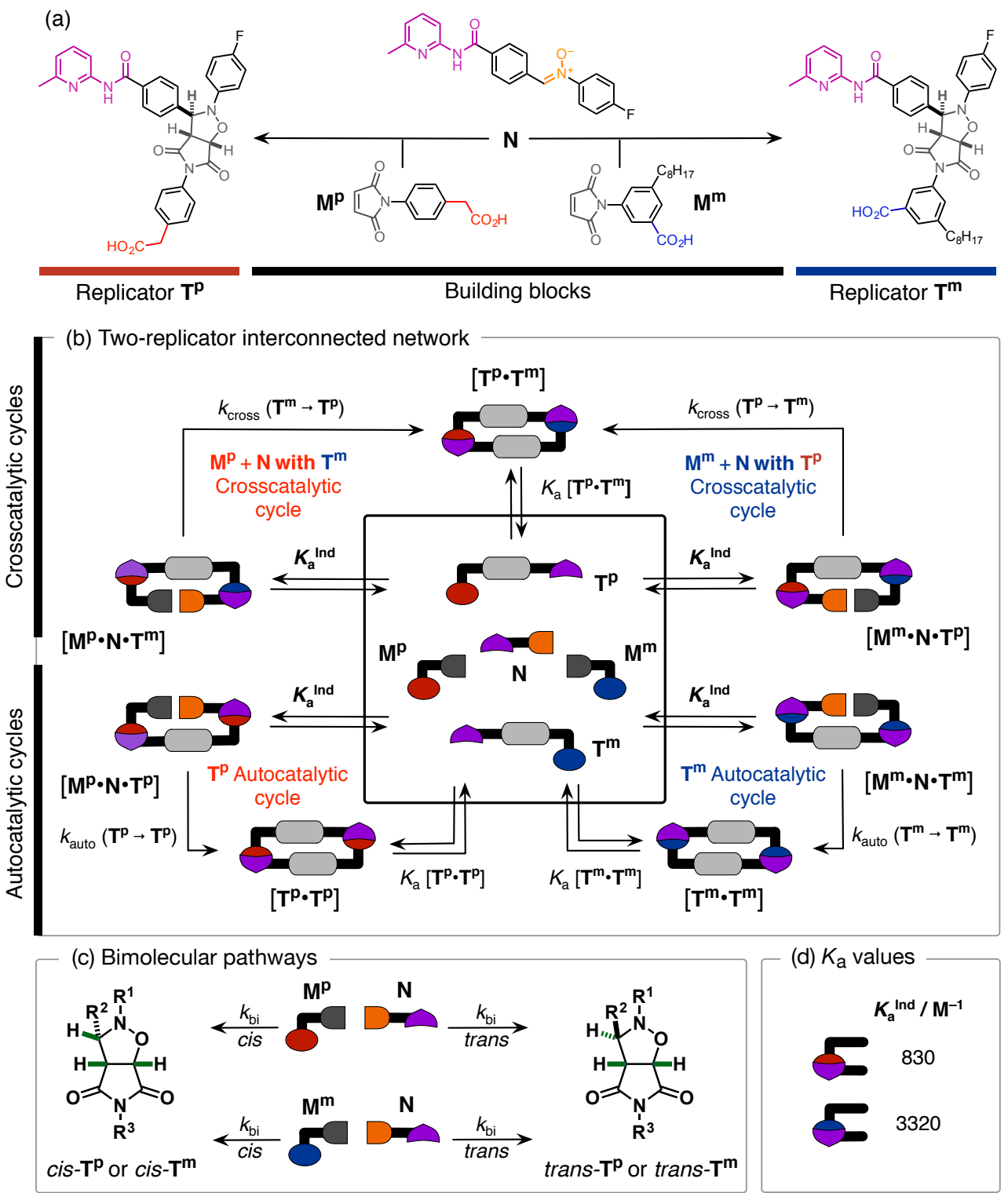

Figure 1. (a) A network of two replicators, $\mathbf{T}^{\mathbf{p}}$ and $\mathbf{T}^{\mathbf{m}}$, can be constructed using the 1,3-dipolar cycloaddition reactions of two maleimides, $\mathbf{M}^{\mathbf{p}}$ and $\mathbf{M}^{\mathbf{m}}$, and nitrone $\mathbf{N}$. Superscript labels $\mathrm{p}$ and $\mathrm{m}$ represent the para and meta location of the carboxylic acid recognition site. (b) Maleimides $\mathbf{M}^{\mathbf{p}}$ and $\mathbf{M}^{\mathbf{m}}$ can react with nitrone $\mathbf{N}$ to form two replicators, $\mathbf{T}^{\mathbf{p}}$ and $\mathbf{T}^{\mathbf{m}}$ (central square). Each of these templates can theoretically take part in auto- and crosscatalytic pathways. (c) Maleimides $\mathbf{M}^{\mathbf{p}}$ and $\mathbf{M}^{\mathbf{m}}$ can react with nitrone $\mathbf{N}$ also via template-independent pathways, resulting in the formation of catalytically active trans diastereoisomers and catalytically inert cis diastereoisomers of $\mathbf{T}^{\mathbf{p}}$ and $\mathbf{T}^{\mathbf{m}}$. (d) The recognition between the network components is governed by specific association constants. 


\section{Results and discussion}

The first step in the analysis of the $\mathbf{T}^{\mathbf{p}} \mathbf{-} \mathbf{T}^{\mathbf{m}}$ network is the examination of individual bimolecular recognition-independent pathways leading to $\mathbf{T}^{\mathbf{p}}$ and $\mathbf{T}^{\mathbf{m}}$. Accordingly, we examined (Figure $\mathbf{2}$ ) the reaction of nitrone $\mathbf{N}$ with two control, recognition-disabled maleimides, $\mathbf{M}^{\mathbf{p C}}$ and $\mathbf{M}^{\mathbf{m C}}$. Details of the synthetic procedures utilized in the syntheses of all reaction components are provided in the Supporting Information. The kinetic analyses of all reaction pathways, facilitated by the presence of the aryl fluorine atom present in nitrone $\mathbf{N}$, and all $\mathbf{N}$-derived cycloadducts, were performed using $470.3 \mathrm{MHz}$ ${ }^{19} \mathrm{~F}\left\{{ }^{1} \mathrm{H}\right\}$ NMR spectroscopy. In all kinetic experiments reported in this study, one or both of the maleimides and the nitrone $([\mathbf{M}]=[\mathbf{N}]=5 \mathrm{mM})$ were allowed to react in $\mathrm{CDCl}_{3}$ at $5{ }^{\circ} \mathrm{C}$, and the reaction progress was monitored by recording $470.3 \mathrm{MHz}{ }^{19} \mathrm{~F}\left\{{ }^{1} \mathrm{H}\right\}$ NMR spectra every 30 minutes over a period of $16 \mathrm{~h}$. The concentrations of the reaction components were determined at each time point relative to 1-bromo-2-fluoro-4-nitrobenzene, which was present as an internal standard.
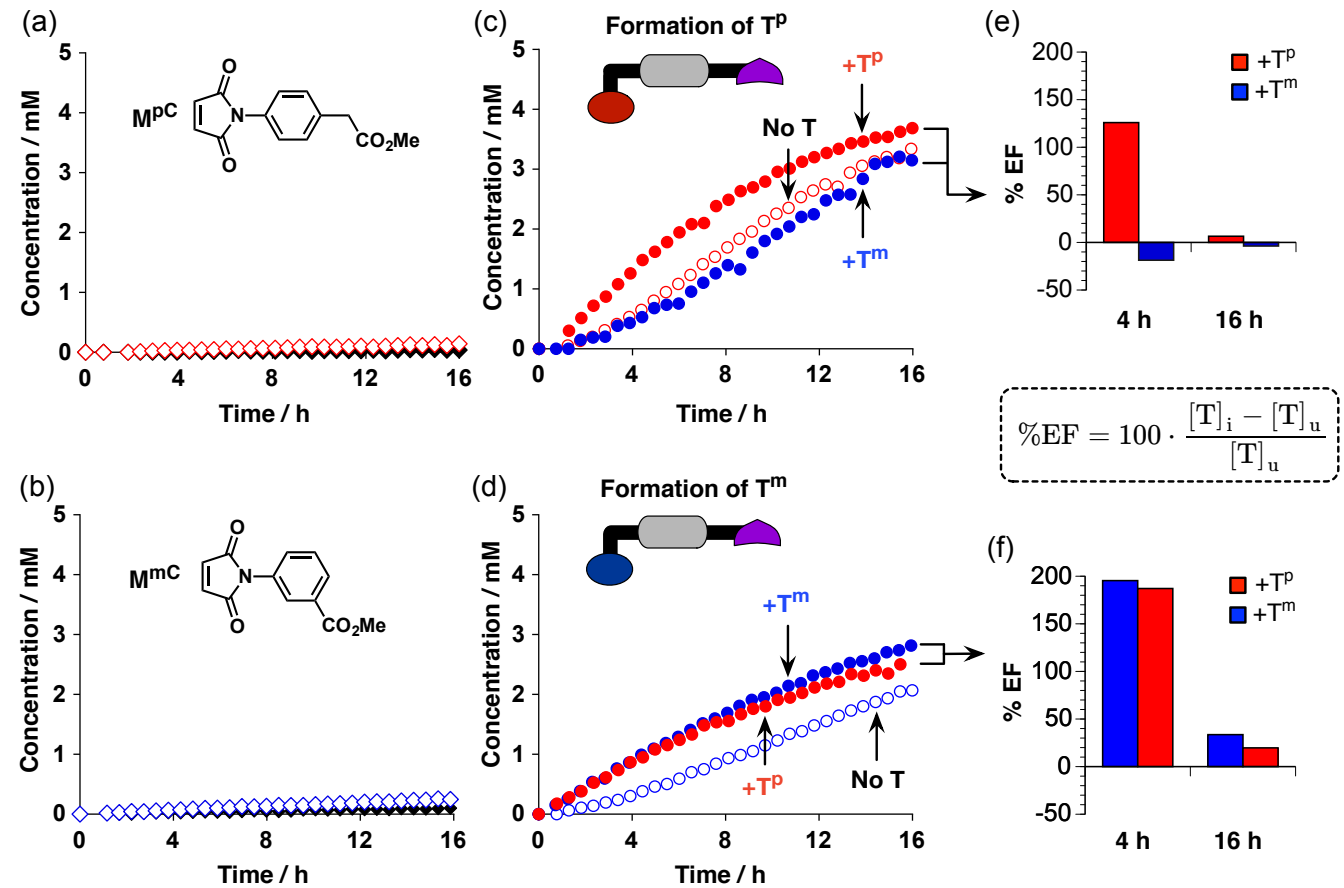

Figure 2. Kinetic experiments examining the reaction of $\mathbf{N}$ with recognition-disabled maleimides (a) $\mathbf{M}^{\mathbf{p C}}$, and (b) $\mathbf{M}^{\mathbf{m C}}$, and recognition-enabled maleimides (c) $\mathbf{M}^{\mathbf{p}}$, and (d) $\mathbf{M}^{\mathbf{m}}$, as determined by $470.3 \mathrm{MHz}{ }^{19} \mathrm{~F}\left\{{ }^{1} \mathrm{H}\right\} \mathrm{NMR}$ spectroscopy relative to 1-bromo-2-fluoro-4-nitrobenzene as an internal standard. Formation of recognition-disabled cycloadducts trans$\mathbf{T}^{\mathbf{p C}}$ (empty red diamonds), trans- $\mathbf{T}^{\mathrm{mC}}$ (empty blue diamonds) and the corresponding cis cycloadducts (filled black diamonds) in (a) and (b) proceeds slowly and unselectively. (c) Formation of replicator trans- $\mathbf{T}^{\mathbf{p}}$ (no cis product was detected) was examined in the absence of template (empty red circles), and in the presence of trans-T $\mathbf{T}^{\mathbf{p}}$ (filled red circles) and trans $-\mathbf{T}^{\mathbf{m}}$ (filled blue circles). (d) Formation of replicator trans $-\mathbf{T}^{\mathbf{m}}$ (cis- $\mathbf{T}^{\mathbf{m}}$ formed $<0.5 \mathrm{mM}$ in each case, data omitted for clarity) was examined in the absence of template (empty blue circles) and in the presence of trans-T $\mathbf{T}^{\mathrm{m}}$ (filled blue circles) and trans- $\mathbf{T}^{\mathbf{p}}$ (filled red circles). Graphs in (e) and (f) show the percentage enhancement factors (\%EFs) determined in template-instructed $\left([\mathrm{T}]_{\mathrm{i}}\right.$ ) experiments (filled symbols in (c) and (d)) relative to the corresponding uninstructed experiments $\left([\mathrm{T}]_{\mathrm{u}}\right)$ (empty symbols in (c) and (d)). Reaction conditions: [all reactants] $=5 \mathrm{mM}, 5{ }^{\circ} \mathrm{C}, \mathrm{CDCl}_{3}, 16 \mathrm{~h} . \mathrm{In}$ each case, instructing template was added at $20 \mathrm{~mol} \%(1 \mathrm{mM})$. Note that the vertical scale in (a) to (d) is identical in order to facilitate direct comparison of reaction conversions. 
The control maleimides do not possess the carboxylic acid recognition site required for successful recognition of the amidopyridine unit on nitrone component $\mathbf{N}$ and the absence of recognition-mediated reactivity is clearly evident in the reaction profiles determined for the reaction of $\mathbf{M}^{\mathbf{p C}}$ with $\mathbf{N}$ (Figure 2a), and $\mathbf{M}^{\mathrm{mC}}$ with $\mathbf{N}$ (Figure $\mathbf{2 b}$ ). The formation of both recognition-disabled trans and cis diastereoisomers of $\mathbf{T}^{\mathbf{p C}}$ and $\mathbf{T}^{\mathrm{mC}}$ proceeded very slowly. After $4 \mathrm{~h}$, trans- $\mathbf{T}^{\mathbf{p C}}$ reached $0.03 \mathrm{mM}$ (Figure 3a), while cis- $\mathbf{T}^{\mathbf{p C}}$ was below the limit of detection at this time. After $16 \mathrm{~h}$, the concentration of these two diastereoisomers increased to $0.14 \mathrm{mM}$ and $0.04 \mathrm{mM}$ for trans and cis, respectively ([trans $] /[$ cis $]=3.8$ ). By contrast, the formation of $\mathbf{T}^{\mathbf{m C}}$ proceeded slightly more efficiently, and the trans and cis cycloadducts reached concentrations of $0.07 \mathrm{mM}$ and $0.02 \mathrm{mM}$, respectively, after $4 \mathrm{~h}$. At $t=16 \mathrm{~h}$, their concentration increased further to $0.24 \mathrm{mM}$ and $0.10 \mathrm{mM}([$ trans $] /[$ cis $]=2.5)$-almost twice as high as those determined for $\mathbf{T}^{\mathbf{p C}}$. These results demonstrated that (i) in the absence of the carboxylic acid recognition site, the formation of templates can proceed only via the slow templateindependent pathways, and (ii) formation of $\mathbf{T}^{\mathrm{mC}}$ proceeds noticeably faster than $\mathbf{T}^{\mathrm{pC}}$, suggesting that replicator $\mathbf{T}^{\mathbf{m}}$ might be able to exploit the template-mediated cycle at an earlier time point in the reaction that $\mathbf{T}^{\mathbf{p}}$.

Next, we examined the formation of replicators $\mathbf{T}^{\mathbf{p}}$ (Figure $\mathbf{2}$, empty red symbols) and $\mathbf{T}^{\mathbf{m}}$ (Figure 2d, empty blue symbols), from their constituent components. Both reaction profiles are sigmoidal, demonstrating the striking effect of recognition-mediated replication processes on product formation. At $t=4 \mathrm{~h}$, replicator $\mathbf{T}^{\mathbf{p}}$ was formed at a concentration of $0.53 \mathrm{mM}$, with complete diastereoselectivity for the trans cycloadduct (i.e., cis < limit of detection by ${ }^{19} \mathrm{~F}\left\{{ }^{1} \mathrm{H}\right\}$ NMR spectroscopy). This concentration increased further to $3.34 \mathrm{mM}$ after $16 \mathrm{~h}$. The reaction that forms $\mathbf{T}^{\mathbf{m}}$ was shown to be less diastereoselective, affording trans- $\mathbf{T}^{\mathbf{m}}$ and cis- $\mathbf{T}^{\mathbf{m}}$ at $0.30 \mathrm{mM}$ and $0.13 \mathrm{mM}$ after $4 \mathrm{~h}$, respectively. After $16 \mathrm{~h}$, the concentration of these cycloadducts increased to $2.10 \mathrm{mM}$ and 0.40 $\mathrm{mM}$. The ratio of the two diastereoisomer products ([trans]/[cis] $)$ increased from 2.3 at $4 \mathrm{~h}$ to 5.2 after $16 \mathrm{~h}$.

In the next stage of our analysis of this system, the formation of each replicator was examined in the presence of $20 \mathrm{~mol} \%(1 \mathrm{mM})$ of the respective trans template (e.g., $\mathbf{T}^{\mathbf{p}}$ added to $\mathbf{M}^{\mathbf{p}}$ and $\mathbf{N}$ ) in order to test whether $\mathbf{T}^{\mathbf{p}}$ and $\mathbf{T}^{\mathbf{m}}$ possess the capacity to template their own formation. The reaction profile for the formation of $\mathbf{T}^{\mathbf{p}}$ in the presence of $\mathbf{T}^{\mathbf{p}}$ (Figure $\mathbf{2} \mathbf{c}$, filled red symbols) and $\mathbf{T}^{\mathbf{m}}$ in the presence of $\mathbf{T}^{\mathbf{m}}$ (Figure 2d, filled blue symbols) revealed disappearance of the lag period in each case, thereby confirming the abilities of $\mathbf{T}^{\mathbf{p}}$ and $\mathbf{T}^{\mathbf{m}}$ to self-replicate. In the presence of the autocatalytic template $\mathbf{T}^{\mathbf{p}}$, formation of $\mathbf{T}^{\mathbf{p}}$ proceeded with significantly increased efficiency, reaching a 
concentration of $1.26 \mathrm{mM}$ after $4 \mathrm{~h}$, and $3.69 \mathrm{mM}$ after $16 \mathrm{~h}$. As expected, the addition of preformed template induces the most striking enhancement in the concentration of replicator at early reaction times. The enhancement in the rate of formation of trans $-\mathbf{T}^{\mathbf{m}}$ was, in contrast, less pronounced. The concentration of trans $-\mathbf{T}^{\mathbf{m}}$ reached $0.86 \mathrm{mM}$ and $2.82 \mathrm{mM}$ after 4 and $16 \mathrm{~h}$, respectively. Catalyticallyinert $c i s-\mathbf{T}^{\mathbf{m}}$ reached a concentration of $0.09 \mathrm{mM}$ and $0.32 \mathrm{mM}$ after 4 and $16 \mathrm{~h}$, giving [trans]/[cis] ratios of 10.1 and 8.1 , respectively.

Thus far, the kinetic analyses confirmed that both $\mathbf{T}^{\mathbf{p}}$ and $\mathbf{T}^{\mathbf{m}}$ are capable of self-replication. Next, we examined the two crosscatalytic pathways- $\mathbf{T}^{\mathbf{m}}$ acting as a template for the formation of $\mathbf{T}^{\mathbf{p}}$ (Figure 2c, filled blue symbols) and vice versa (Figure 2d, filled red symbols). To this end, each set of reactants was instructed with $20 \mathrm{~mol} \%$ of the corresponding crosscatalytic template. Interestingly, the addition of $\mathbf{T}^{\mathbf{m}}$ to the reactants required for the formation of $\mathbf{T}^{\mathbf{p}}$ resulted in no observable enhancement in the concentration of $\mathbf{T}^{\mathbf{p}}$. In fact, no change in the lag period for $\mathbf{T}^{\mathbf{p}}$ formation was observed and the reaction profile determined in the presence of $\mathbf{T}^{\mathbf{m}}$ was essentially identical to that obtained in the absence of instruction. In terms of concentration, cycloadduct trans- $\mathbf{T}^{\mathbf{p}}$ reached $0.43 \mathrm{mM}$ after $4 \mathrm{~h}-$ similar to that $(0.53 \mathrm{mM})$ reached in the absence of any instructing template. After $16 \mathrm{~h}$, this concentration increased to $3.15 \mathrm{mM}$. Strikingly, however, instructing the building blocks required for the formation of $\mathbf{T}^{\mathbf{m}}$ with template $\mathbf{T}^{\mathbf{p}}$ resulted in the unambiguous disappearance of the lag period, demonstrating that $\mathbf{T}^{\mathbf{p}}$ can template the formation of trans $-\mathbf{T}^{\mathbf{m}}$. After $4 \mathrm{~h}$, trans $-\mathbf{T}^{\mathbf{m}}$ and cis- $\mathbf{T}^{\mathbf{m}}$ were formed at concentrations of $0.87 \mathrm{mM}$ and $0.08 \mathrm{mM}$, respectively. These concentrations increased further after $16 \mathrm{~h}$, reaching $2.52 \mathrm{mM}$ and $0.22 \mathrm{mM}$, respectively ([trans $] /[$ cis $]$ ratios of 10.3 and 11.4$)$. The slight increase in diastereoselectivity for the trans product in the presence of preformed $\mathbf{T}^{\mathbf{p}}$ compared to $\mathbf{T}^{\mathbf{m}}$ suggests that template $\mathbf{T}^{\mathbf{p}}$, which locates the two recognition sites at a slightly different separation and geometry with respect to each other than $\mathbf{T}^{\mathbf{m}}$, can promote the formation of the trans diastereoisomer more effectively than $\mathbf{T}^{\mathbf{m}}$.

In order to quantify the changes in replication efficiency observed in the template-instructed experiments relative to those lacking any instruction, we calculated the percentage enhancement factor $^{18}(\% \mathrm{EF})$ for each trans product determined after both $4 \mathrm{~h}$ and $16 \mathrm{~h}$ (Figure 2). Examination of these results for $\mathbf{T}^{\mathbf{p}}$ (Figure $\mathbf{2 e}$ ) and $\mathbf{T}^{\mathbf{m}}$ (Figure $\mathbf{2 f}$ ) reveals a number of trends. Firstly, the $\% \mathrm{EFs}$ are significantly higher after $4 \mathrm{~h}$ than after $16 \mathrm{~h}$, reflecting the fact that the presence of preformed template exerts a stronger effect at earlier reaction times when the overall concentration of catalytically active template within the uninstructed reaction mixture is typically low. Further, Figure 2e shows that the addition of $\mathbf{T}^{\mathbf{p}}$ to the building blocks required for its own formation enhanced its formation significantly: $138 \pm 7 \%$ at $4 \mathrm{~h}$, and $10 \pm 1 \%$ at $16 \mathrm{~h}$. In contrast, the addition of $\mathbf{T}^{\mathrm{m}}$ to the same mixture 
of building blocks resulted in a suppression of $\mathbf{T}^{\mathbf{p}}$ formation $(4 \mathrm{~h}=-19 \pm 5 \%, \quad 16 \mathrm{~h}=-6 \pm 1 \%)$ relative to the uninstructed reaction. This observation suggests that $\mathbf{T}^{\mathbf{p}}$ might be sequestered within the $\left[\mathbf{T}^{\mathbf{p}} \cdot \mathbf{T}^{\mathbf{m}}\right.$ ] heteroduplex, which reduces the quantity of free template available for reaction. The same analysis of the enhancements determined for $\mathbf{T}^{\mathbf{m}}$ reveals that the addition of autocatalytic template $\mathbf{T}^{\mathbf{m}}(4 \mathrm{~h}=185 \quad \pm$ $15 \%, \quad 16 \mathrm{~h}=36 \pm 2 \%$ ) affords a marginally higher enhancement than the addition of crosscatalytic template $\mathbf{T}^{\mathbf{p}}(4 \mathrm{~h}=187 \pm 16 \%, \quad 16 \mathrm{~h}=22 \pm 1 \%)$. Overall, a comparison of the EFs showed that the addition of preformed template produces a more significant change in the formation of $\mathbf{T}^{\mathbf{m}}$ than in the formation of $\mathbf{T}^{\mathbf{p}}$. Most likely, this difference can be attributed to the fact that replicator $\mathbf{T}^{\mathbf{m}}$ is less efficient at making itself than $\mathbf{T}^{\mathbf{p}}$ in the absence of template and is therefore affected less by the decreasing availability of the reagents required for its formation at longer reaction times. In summary, the comprehensive evaluation of all auto- and crosscatalytic pathways available to $\mathbf{T}^{\mathbf{p}}$ and $\mathbf{T}^{\mathbf{m}}$ confirmed that only three catalytic channels out of the four possible operate efficiently.

\section{Kinetic fitting and simulations}

In order to develop a better understanding of the differences in the kinetic behaviors of $\mathbf{T}^{\mathbf{p}}$ and $\mathbf{T}^{\mathbf{m}}$ in terms of the key kinetic and thermodynamic parameters that characterize the auto- and crosscatalytic cycles, we fitted the reaction time courses shown in Figure 3 to appropriate kinetic models (see Supporting Information). These kinetic models describe the interactions and reactions leading to the formation of $\mathbf{T}^{\mathbf{p}}$ or $\mathbf{T}^{\mathbf{m}}$ and using established protocols, ${ }^{8 \mathrm{a}, 13 \mathrm{~b}, 14 \mathrm{a}}$ we were able to determine the bimolecular reaction rate constants $\left(k_{\mathrm{bi}}\right)$ for the formation of both trans and cis cycloadducts, the unimolecular rate constants $\left(k_{\text {auto }}, k_{\text {cross }}\right)$, and duplex association constants $\left(K_{\mathrm{a}}^{\text {Duplex }}\right)$ pertaining to all auto- and crosscatalytic pathways (Table 1).

Table 1. Overview of rate and duplex association constants determined using SimFit ${ }^{13 \mathrm{~b}}$ for the bimolecular and recognition-mediated auto- and crosscatalytic pathways of replicators trans- $\mathbf{T}^{\mathbf{p}}$ and trans-T $\mathbf{T}^{\mathbf{m}}$. The rate constants for the formation of catalytically inactive cis diastereoisomers of $\mathbf{T}^{\mathbf{p}}$ and $\mathbf{T}^{\mathbf{m}}$ through the corresponding bimolecular templateindependent pathways were determined to be 0.431 and $0.70410^{-4} \mathrm{M}^{-1} \mathrm{~s}^{-1}$, respectively.

\begin{tabular}{|c|c|c|c|}
\hline \multicolumn{2}{|r|}{ Reactions } & $\boldsymbol{k}$ & $\mathbf{E M}_{\text {kinetic }} / \mathbf{M}$ \\
\hline Bimolecular & $\mathbf{N}+\mathbf{M}^{\mathbf{p}} \rightarrow$ trans $-\mathbf{T}^{\mathbf{p}}$ & 1.12 & - \\
\hline$k_{\mathrm{bi}} / 10^{-4} \mathrm{M}^{-1} \mathrm{~s}^{-1}$ & $\mathbf{N}+\mathbf{M}^{\mathrm{m}} \rightarrow$ trans $-\mathbf{T}^{\mathrm{m}}$ & 1.79 & - \\
\hline Autocatalytic & {$\left[\mathbf{N} \bullet \mathbf{M}^{\mathbf{p}} \cdot\right.$ trans $\left.-\mathbf{T}^{\mathbf{p}}\right] \rightarrow\left[\right.$ trans $-\mathbf{T}^{\mathbf{p}} \bullet$ trans $\left.-\mathbf{T}^{\mathbf{p}}\right]$} & 71.6 & 64.0 \\
\hline$k_{\text {auto }} / 10^{-4} \mathrm{~s}^{-1}$ & {$\left[\mathbf{N} \bullet \mathbf{M}^{\mathbf{m}} \bullet\right.$ trans $\left.-\mathbf{T}^{\mathrm{m}}\right] \rightarrow\left[\right.$ trans $-\mathbf{T}^{\mathbf{m}} \bullet$ trans $\left.-\mathbf{T}^{\mathbf{m}}\right]$} & 17.0 & 9.47 \\
\hline Crosscatalytic & {$\left[\mathbf{N} \bullet \mathbf{M}^{\mathbf{p}} \cdot\right.$ trans $\left.-\mathbf{T}^{\mathrm{m}}\right] \rightarrow\left[\right.$ trans $-\mathbf{T}^{\mathrm{p}} \bullet$ trans $\left.-\mathbf{T}^{\mathrm{m}}\right]$} & 4.67 & 4.21 \\
\hline $\boldsymbol{k}_{\text {cross }} / 10^{-4} \mathrm{~s}^{-1}$ & {$\left[\mathbf{N} \bullet \mathbf{M}^{\mathrm{m}} \bullet\right.$ trans $\left.-\mathbf{T}^{\mathrm{p}}\right] \rightarrow\left[\right.$ trans $-\mathbf{T}^{\mathrm{p}} \bullet$ trans $\left.-\mathbf{T}^{\mathrm{m}}\right]$} & 20.3 & 18.3 \\
\hline
\end{tabular}




\begin{tabular}{|c|c|c|c|}
\hline \multicolumn{2}{|r|}{ Equilibria } & $\boldsymbol{K}_{\mathrm{a}}$ & $\mathbf{E M}_{\text {thermo }} / \mathbf{M}$ \\
\hline \multirow{2}{*}{$\underset{K_{\mathrm{a}}^{\text {Ind }} / \mathbf{M}^{-1}}{\text { Binary }}$} & $\mathbf{N}+\mathbf{M}^{\mathrm{p}} \leftrightarrow\left[\mathbf{N} \cdot \mathbf{M}^{\mathrm{p}}\right]$ & 830 & - \\
\hline & $\mathbf{N}+\mathbf{M}^{\mathbf{m}} \leftrightarrow\left[\mathbf{N} \cdot \mathbf{M}^{\mathbf{m}}\right]$ & 3320 & - \\
\hline \multirow{3}{*}{$\underset{K_{\mathrm{a}}^{\text {Duplex }} / 1^{6} \mathrm{M}^{-1}}{\text { Template }}$} & trans $-\mathbf{T}^{\mathbf{p}}+$ trans $-\mathbf{T}^{\mathbf{p}} \leftrightarrow\left[\right.$ trans $-\mathbf{T}^{\mathbf{p}} \bullet$ trans $\left.-\mathbf{T}^{\mathbf{p}}\right]$ & 17.9 & 26.0 \\
\hline & trans $-\mathbf{T}^{\mathbf{m}}+$ trans $-\mathbf{T}^{\mathrm{m}} \leftrightarrow\left[\right.$ trans $-\mathbf{T}^{\mathrm{m}} \bullet$ trans $\left.-\mathbf{T}^{\mathbf{m}}\right]$ & 68.6 & 6.22 \\
\hline & trans $-\mathbf{T}^{\mathbf{p}}+$ trans $-\mathbf{T}^{\mathbf{m}} \leftrightarrow\left[\right.$ trans $-\mathbf{T}^{\mathbf{p}} \bullet$ trans $\left.-\mathbf{T}^{\mathbf{m}}\right]$ & 35.0 & 12.7 \\
\hline
\end{tabular}

These parameters, together with association values for the formation of $[\mathbf{M} \cdot \mathbf{N}]$ complexes $\left(K_{\mathrm{a}}^{\text {Ind }}\right)$ were subsequently used to calculate the kinetic effective molarity ${ }^{19}\left(\mathrm{EM}_{\text {kientic }}\right)$ and thermodynamic effective molarity $^{20}\left(\mathrm{EM}_{\text {thermo}}\right)$ for each replication pathway. Examination of the parameters shown in Table 1 reveals that both trans and cis diastereoisomeric products of $\mathbf{T}^{\mathbf{m}}$ are formed with a higher bimolecular rate constant their $\mathbf{T}^{\mathbf{p}}$ counterparts. The initial advantage provided to $\mathbf{T}^{\mathrm{m}}$ replicator as a result of the higher bimolecular rate $\left(\mathbf{T}^{\mathbf{m}}\right.$ should reach the concentration required for initiating autocatalysis earlier than $\mathbf{T}^{\mathbf{p}}$ ) is countered by the lower $k_{\text {auto }}$ for the formation of $\mathbf{T}^{\mathbf{m}}$. Comparison of the kinetic profiles and values of $\mathrm{EM}_{\text {kinetic }}$ determined for $\mathbf{T}^{\mathbf{p}}$ and $\mathbf{T}^{\mathbf{m}}$ confirmed that, in isolation, $\mathbf{T}^{\mathbf{p}}$ is significantly more efficient at directing its own formation than $\mathbf{T}^{\mathbf{m}}$. The fitting procedure allowed the determination of the association constants ${ }^{21}$ for replicator homoduplexes for trans- $\mathbf{T}^{\mathbf{p}}\left(17.9 \times 10^{6} \mathrm{M}^{-1}\right)$ and trans- $\mathbf{T}^{\mathbf{m}}(68.6$ $\times 10^{6} \mathrm{M}^{-1}$ ), respectively. The higher stability of the $\left[\mathbf{T}^{\mathbf{m}} \cdot \mathbf{T}^{\mathbf{m}}\right]$ duplex relative to the $\left[\mathbf{T}^{\mathbf{p}} \cdot \mathbf{T}^{\mathbf{p}}\right]$ duplex indicates that $\mathbf{T}^{\mathbf{m}}$ is hindered more significantly by product inhibition than $\mathbf{T}^{\mathbf{p}}$. Interestingly, while $\mathbf{T}^{\mathbf{m}}$ is associated with a higher duplex stability, it possesses lower $\mathbf{E M}_{\text {thermo }}$ than $\mathbf{T}^{\mathbf{p}}$. This observation suggests a lower degree of complementarity and, hence, cooperativity within the $\mathbf{T}^{\mathrm{m}}$ duplex.

The fitting procedure employed in the determination of kinetic parameters pertaining to the two crosscatalytic pathways required the introduction of an additional parameter-i.e., the association constant for the formation of heteroduplex $\left[\mathbf{T}^{\mathbf{p}} \cdot \mathbf{T}^{\mathrm{m}}\right]$. This heteroduplex contains one more rotatable bond than $\left[\mathbf{T}^{\mathbf{m}} \cdot \mathbf{T}^{\mathbf{m}}\right]$ and one rotatable bond less than $\left[\mathbf{T}^{\mathbf{p}} \cdot \mathbf{T}^{\mathbf{p}}\right]$ and therefore, its stability should be bracketed by the stabilities of the two homoduplexes. Applying rotor increments, as described ${ }^{18 a}$ by Page and Jencks, the stability of $\left[\mathbf{T}^{\mathbf{p}} \cdot \mathbf{T}^{\mathbf{m}}\right]$ was estimated as $35.0 \times 10^{6} \mathrm{M}^{-1}$, and this value was employed in the determination of $k_{\text {cross }}$ for the formation of each trans product on the corresponding crosscatalytic template (Table 1).

The parameters obtained through the kinetic fitting of crosscatalytic kinetic data allowed us to assess the differences observed in the corresponding time course profiles of both replicators. Specifically, $\mathbf{T}^{\mathbf{m}}$ was found to be significantly worse at catalyzing the formation of $\mathbf{T}^{\mathbf{p}}$ than $\mathbf{T}^{\mathbf{p}}$ was at catalyzing its own formation. In fact, the $\mathrm{EM}_{\text {kinetic }}$ for this crosscatalytic pathway was $c a .15 \times$ smaller 
than that determined for the autocatalytic pathway leading to $\mathbf{T}^{\mathbf{p}}$. By contrast, the $\mathrm{EM}_{\text {kinetic }}$ for the crosscatalytic pathway that involves $\mathbf{T}^{\mathbf{m}}$ being made on $\mathbf{T}^{\mathbf{p}}$ was actually somewhat higher (18.3 $\left.\mathrm{M}\right)$ than the corresponding autocatalytic process $(9.47 \mathrm{M})$. These differences in the relative efficiencies of the auto- and crosscatalytic pathways directed by $\mathbf{T}^{\mathbf{p}}$ and $\mathbf{T}^{\mathbf{m}}$ can explain the absence of a template effect for $\mathbf{T}^{\mathbf{p}}$ being synthesized on a $\mathbf{T}^{\mathbf{m}}$ template.

An important consequence of the order of stabilities determined for the duplexes in the full network $\left(\left[\mathbf{T}^{\mathbf{m}} \cdot \mathbf{T}^{\mathbf{m}}\right]>\left[\mathbf{T}^{\mathbf{p}} \cdot \mathbf{T}^{\mathbf{m}}\right]>\left[\mathbf{T}^{\mathbf{p}} \cdot \mathbf{T}^{\mathbf{p}}\right]\right)$, is the preferential incorporation of $\mathbf{T}^{\mathbf{p}}$ within the more stable heteroduplex $\left[\mathbf{T}^{\mathbf{p}} \cdot \mathbf{T}^{\mathbf{m}}\right]$ in situations where $\mathbf{T}^{\mathbf{m}}$ is present at significant concentrations. The kinetic data derived from NMR spectroscopy reveals that the exchange between the various template species present in solution is fast on the NMR chemical shift timescale (i.e., only a single resonance arising from the trans isoxazolidine proton is observed for each replicator). For this reason, we exploited kinetic simulations and the relevant reaction parameters obtained through fitting to demonstrate how the presence of $\mathbf{T}^{\mathbf{m}}$ serves to decrease the amount of catalytically active $\mathbf{T}^{\mathbf{p}}$ in solution. Specifically, early in the reaction where $\mathbf{T}^{\mathbf{p}}$ is being synthesized in the presence of preformed $\mathbf{T}^{\mathbf{m}}$ (Figure 3a), the higher stability of the $\left[\mathbf{T}^{\mathbf{p}} \cdot \mathbf{T}^{\mathbf{m}}\right]$ heteroduplex relative to that of the $\left[\mathbf{T}^{\mathbf{p}} \cdot \mathbf{T}^{\mathbf{p}}\right]$ homoduplex leads to the template $\mathbf{T}^{\mathbf{p}}$ formed within the system being sequestered into the more stable heteroduplex. The higher proportion of $\mathbf{T}^{\mathbf{p}}$ in the $\left[\mathbf{T}^{\mathbf{p}} \cdot \mathbf{T}^{\mathbf{m}}\right]$ heteroduplex than in the $\left[\mathbf{T}^{\mathbf{p}} \cdot \mathbf{T}^{\mathbf{p}}\right]$ homoduplex reduces the catalytic availability of this template and, also, the overall rate of production of $\mathbf{T}^{\mathbf{p}}$ because the $\left[\mathbf{T}^{\mathbf{p}} \cdot \mathbf{T}^{\mathbf{m}}\right.$ ] heteroduplex has a lower $K_{\mathrm{d}}$. At a certain point in the reaction, however, the concentration of $\mathbf{T}^{\mathbf{p}}$ reaches a critical threshold and the fraction of $\mathbf{T}^{\mathbf{p}}$ bound in the $\left[\mathbf{T}^{\mathbf{p}} \cdot \mathbf{T}^{\mathbf{p}}\right]$ homoduplex becomes higher than the fraction present within the $\left[\mathbf{T}^{\mathbf{p}} \cdot \mathbf{T}^{\mathbf{m}}\right]$ heteroduplex.

By contrast, this order of stabilities exerts the opposite effect on the crosscatalytic pathway where the formation of $\mathbf{T}^{\mathbf{m}}$ is simulated in the presence of $\mathbf{T}^{\mathbf{p}}$ (Figure $\mathbf{3 b}$ ). In this situation, $\operatorname{trans}-\mathbf{T}^{\mathbf{p}}$ is the dominant product early in the reaction and therefore, the molecules of $\mathbf{T}^{\mathbf{m}}$ formed through the crosscatalytic pathway are present predominantly in the form of the heteroduplex $\left[\mathbf{T}^{\mathbf{p}} \cdot \mathbf{T}^{\mathbf{m}}\right]$. This heteroduplex is less stable than the $\left[\mathbf{T}^{\mathbf{m}} \cdot \mathbf{T}^{\mathbf{m}}\right]$ duplex that is present exclusively in the absence of $\mathbf{T}^{\mathbf{p}}$, resulting in higher concentrations of monomeric of $\mathbf{T}^{\mathbf{m}}$ at early time points. Nevertheless, the affinity of $\mathbf{T}^{\mathbf{p}}$ for $\mathbf{M}^{\mathbf{m}}$ and $\mathbf{N}$ is lower than the affinity of $\mathbf{T}^{\mathbf{m}}$ for these components, and as the concentration of $\mathbf{T}^{\mathbf{m}}$ continues to increase, homoduplex $\left[\mathbf{T}^{\mathbf{m}} \cdot \mathbf{T}^{\mathbf{m}}\right]$ becomes the dominant species in solution, and the efficiency of the crosscatalytic pathway $\left(\mathbf{T}^{\mathbf{p}} \rightarrow \mathbf{T}^{\mathbf{m}}\right)$ decreases. 

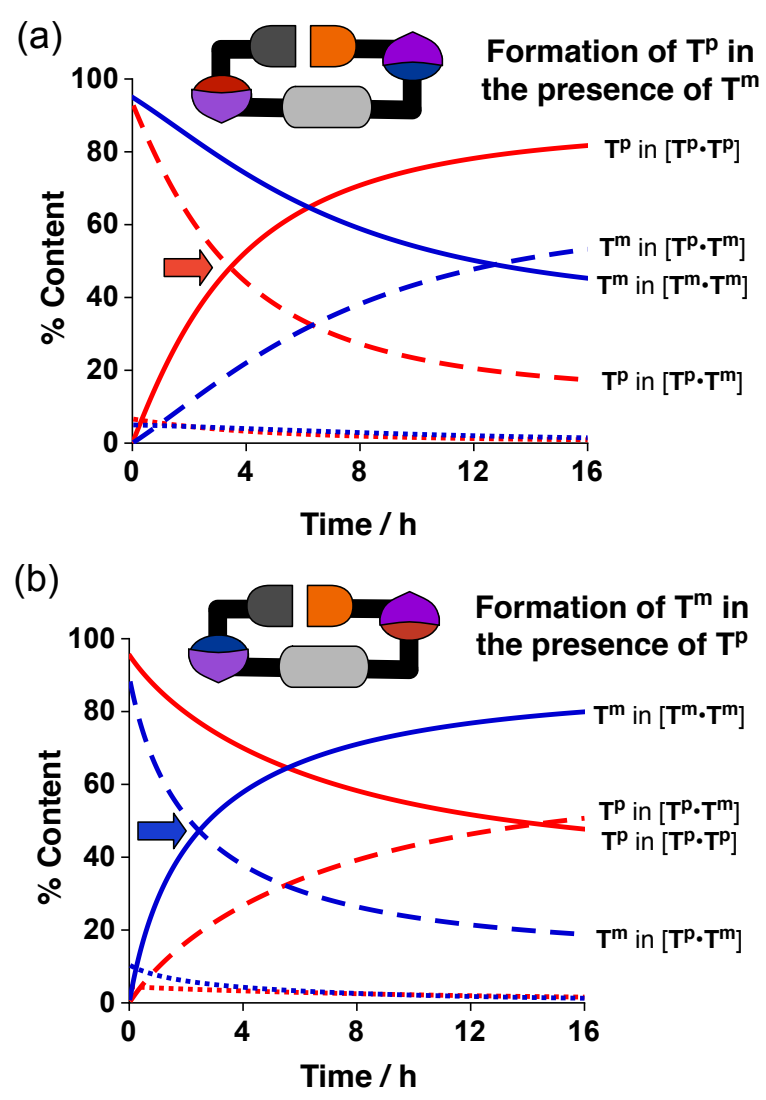

(c)

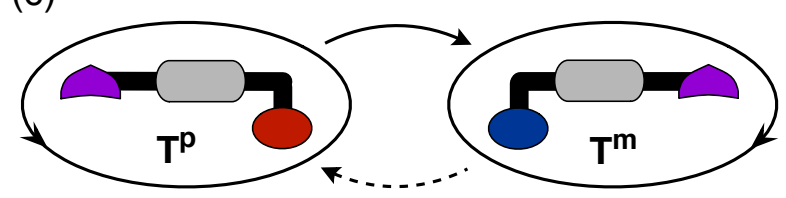

Figure 3. Simulations predict the distribution of templates $\mathbf{T}^{\mathbf{m}}$ and $\mathbf{T}^{\mathbf{p}}$ in homo- (full lines) and heteroduplexes (dashed lines) in experiments where the reagents required for the formation of (a) $\mathbf{T}^{\mathbf{p}}$ are instructed with $20 \mathrm{~mol} \%$ of trans$\mathbf{T}^{\mathbf{m}}(1 \mathrm{mM})$, and (b) the reagents for the formation of $\mathbf{T}^{\mathbf{m}}$ are instructed with $20 \mathrm{~mol} \%$ of trans- $\mathbf{T}^{\mathbf{p}}(1 \mathrm{mM})$. Templates $\mathbf{T}^{\mathbf{p}}$ and $\mathbf{T}^{\mathbf{m}}$ present within the various categories are represented in red and blue, respectively. Dotted lines represent the \% content of $\mathbf{T}^{\mathbf{p}}$ and $\mathbf{T}^{\mathbf{m}}$ in their monomeric form or in other binary complexes. Red and blue arrows highlight the time point in the reaction at which the \% content of the homoduplex of the template being formed is higher than its content in the corresponding heteroduplex. (c) Schematic overview of the catalytic relationship between replicators $\mathbf{T}^{\mathbf{p}}$ and $\mathbf{T}^{\mathbf{m}}$. Dashed line signifies absence of effective catalysis.

\section{Kinetic analysis of competition between replicators}

Kinetic analyses of our two replicators in isolation established clearly that $\mathbf{T}^{\mathbf{p}}$ possesses the capacity to template both its own formation and to crosscatalyze the formation of $\mathbf{T}^{\mathbf{m}}$, while $\mathbf{T}^{\mathbf{m}}$ is capable of autocatalytic activity only. Building on these results, we examined these replicators under conditions where $\mathbf{M}^{\mathbf{p}}$ and $\mathbf{M}^{\mathbf{m}}$ compete for the nitrone $\mathbf{N}$ building block. In order to explore the possibility of directing the reaction network towards selective formation of either $\mathbf{T}^{\mathbf{p}}$ or $\mathbf{T}^{\mathbf{m}}$, we employed a series of template-instructed experiments. In each of these experiments, an equimolar solution $(5 \mathrm{mM})$ containing all three reaction components, $\mathbf{N}, \mathbf{M}^{\mathbf{p}}$, and $\mathbf{M}^{\mathbf{m}}$, was prepared in $\mathrm{CDCl}_{3}$ and the formation of the replicators was monitored at $5{ }^{\circ} \mathrm{C}$ in the absence of any added template using $470.3 \mathrm{MHz}{ }^{19} \mathrm{~F}\left\{{ }^{1} \mathrm{H}\right\}$ 
NMR spectroscopy (see Supporting Information, Figure S8). The instructed experiments examined the formation of $\mathbf{T}^{\mathbf{p}}$ and $\mathbf{T}^{\mathbf{m}}$ in the presence of $20 \mathrm{~mol} \%$ of one or both preformed replicators. A number of scenarios were examined - (i) only trans- $\mathbf{T}^{\mathbf{p}}$ added, (ii) only trans- $\mathbf{T}^{\mathbf{m}}$ added and (iii) both trans- $\mathbf{T}^{\mathbf{p}}$ and trans- $\mathbf{T}^{\mathbf{m}}$ added simultaneously (see Supporting Information, Figure S8). The results of these experiments are summarized in Figure 4. Interestingly, the uninstructed competition experiment revealed that, as a result of the interplay between the recognition and reaction processes taking place simultaneously in the network, the less efficient template trans $^{-} \mathbf{T}^{\mathbf{m}}$ reached a higher concentration than trans $-\mathbf{T}^{\mathbf{p}}$, the replicator found to be more efficient in isolation $\left(\left[\operatorname{trans}-\mathbf{T}^{\mathbf{m}}\right] /\left[\operatorname{trans}-\mathbf{T}^{\mathbf{p}}\right]=2.0\right.$ after $4 \mathrm{~h}$,

Figure 4a).

(a)

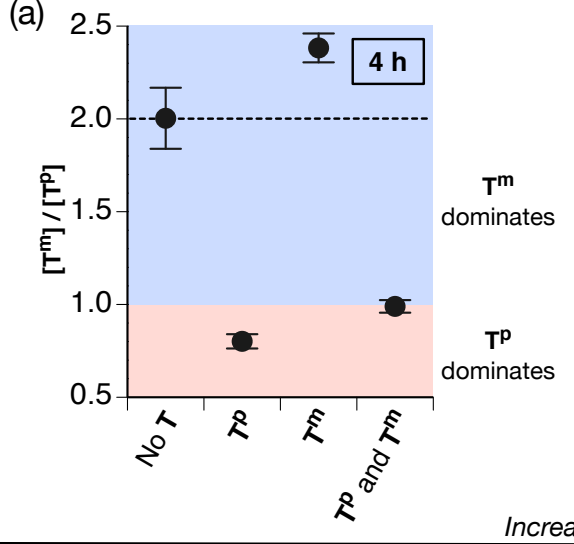

Experiments with no $\mathbf{T}$ and $\mathbf{T}^{\mathrm{m}}$ : selectivity $\downarrow$

Experiments with no $\mathrm{T}^{\mathbf{p}}$ and both $\mathrm{T}^{\mathbf{p}}$ and $\mathrm{T}^{\mathrm{m}}$ : selectivity unchanged (b)

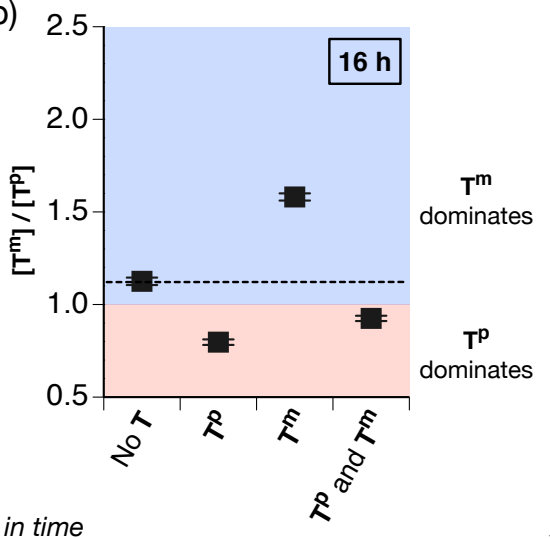

$\mathrm{T}^{\mathrm{p}}$

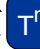

Figure 4. The effect of instructing the $\mathbf{T}^{\mathbf{p}}-\mathbf{T}^{\mathbf{m}}$ network with preformed template (added at $t=0$ ), on the ratio of $\left[\mathbf{T}^{\mathbf{m}}\right] /\left[\mathbf{T}^{\mathbf{p}}\right]$ determined after (a) $4 \mathrm{~h}$ (black circles) and (b) $16 \mathrm{~h}$ (black squares). Dashed lines represent the $\left[\mathbf{T}^{\mathbf{m}}\right] /\left[\mathbf{T}^{\mathbf{p}}\right] \mathrm{ratio}$ determined in the uninstructed kinetic experiments, for comparison. Concentrations were determined using $470.3 \mathrm{MHz}$ ${ }^{19} \mathrm{~F}\left\{{ }^{1} \mathrm{H}\right\}$ NMR spectroscopy $\left(\left[\mathbf{M}^{\mathbf{p}}\right]=\left[\mathbf{M}^{\mathbf{m}}\right]=[\mathbf{N}]=5 \mathrm{mM}\right.$, if present, [template $\left.]=1 \mathrm{mM}, \mathrm{CDCl}_{3}, 5^{\circ} \mathrm{C}\right)$.

In the presence of preformed trans- $\mathbf{T}^{\mathbf{p}}$, added to the reaction mixture at the start of the reaction, the observed outcome was altered significantly - the instructing replicator, trans- $\mathbf{T}^{\mathbf{p}}$, outperformed trans$\mathbf{T}^{\mathbf{m}}$ in the competition for $\mathbf{N}$ and the two products were formed in a ratio of $0.80\left(\left[\right.\right.$ trans $\left.-\mathbf{T}^{\mathbf{m}}\right] /\left[\right.$ trans $\left.-\mathbf{T}^{\mathbf{p}}\right]$ after 4 h, Figure 5a). When preformed trans $-\mathbf{T}^{\mathbf{m}}$ was added at the start of the reaction, the network displayed the opposite behavior-i.e., formation of replicator trans $-\mathbf{T}^{\mathbf{m}}$ was enhanced further ([trans$\left.\mathbf{T}^{\mathbf{m}}\right] /\left[\right.$ trans $\left.-\mathbf{T}^{\mathbf{p}}\right]=2.38$ after 4 h, Figure 5a). Interestingly, when both trans $-\mathbf{T}^{\mathbf{p}}$ and trans $-\mathbf{T}^{\mathbf{m}}$ were used to instruct the replication processes simultaneously, the two replicators were formed at a ratio of 0.99 ([trans $\left.-\mathbf{T}^{\mathbf{m}}\right] /\left[\right.$ trans $\left.-\mathbf{T}^{\mathbf{p}}\right]$ ) after $4 \mathrm{~h}$ (Figure 5a). The simultaneous addition of both $\mathbf{T}^{\mathbf{p}}$ and $\mathbf{T}^{\mathbf{m}}$ enhances the formation of trans $-\mathbf{T}^{\mathbf{p}}$ relative to the uninstructed scenario, nevertheless trans $-\mathbf{T}^{\mathbf{m}}$ remained the dominant species in solution in this experiment after $4 \mathrm{~h}$. This observation can be attributed to the fact 
that the formation of replicator trans- $\mathbf{T}^{\mathbf{m}}$ proceeds through two template-mediated channels, whilst replicator trans- $\mathbf{T}^{\mathbf{p}}$ is formed through a single autocatalytic pathway only.

The ratios of the two replicators, $\left[\right.$ trans $\left.-\mathbf{T}^{\mathbf{m}}\right] /\left[\right.$ trans $\left.-\mathbf{T}^{\mathbf{p}}\right]$, were re-examined after $16 \mathrm{~h}$, revealing a trend similar to that observed for the \%EFs discussed earlier for the auto- and crosscatalytic pathways in isolation. Specifically, the values of $\left[\right.$ trans $\left.-\mathbf{T}^{\mathbf{m}}\right] /\left[\right.$ trans $\left.-\mathbf{T}^{\mathbf{p}}\right]$ at $t=16 \mathrm{~h}$ were determined to be 1.13 , $0.80,1.58$, and 0.93 in the presence of no template, trans $-\mathbf{T}^{\mathbf{p}}$, trans $-\mathbf{T}^{\mathbf{m}}$, and both trans $-\mathbf{T}^{\mathbf{p}}$ and trans$\mathbf{T}^{\mathbf{m}}$, respectively (Figure 5b). Comparison of the ratios determined after 4 and $16 \mathrm{~h}$ showed that the selectivity in experiments instructed with $\mathbf{T}^{\mathbf{p}}$ only changed less over time $(4 \mathrm{~h} \rightarrow 16 \mathrm{~h})$ than the selectivity in experiments employing no template or $\mathbf{T}^{\mathbf{m}}$. These differences in product ratio as a function of time can be attributed to the fact that only a single crosscatalytic pathway is active in this network and thus, while the presence of $\mathbf{T}^{\mathbf{p}}$ affects the formation of both templates, addition of $\mathbf{T}^{\mathbf{m}}$ enhances the production of itself exclusively. Overall, these results demonstrate that the [trans$\left.\mathbf{T}^{\mathbf{m}}\right] /\left[\right.$ trans $\left.-\mathbf{T}^{\mathbf{p}}\right]$ ratio is strongly dependent on both the reaction time and the identity of the instructing template or templates.

\section{Examining the role of the $\left[\mathbf{T}^{\mathrm{p}} \cdot \mathbf{T}^{\mathrm{m}}\right]$ heteroduplex}

The kinetic analyses revealed that the two replicators examined in this study exhibit markedly different replication efficiencies as a result of small structural changes engineered in their molecular frameworks. Although the kinetics of the competition experiments utilized data from ${ }^{19} \mathrm{~F}$ NMR spectroscopy, ${ }^{1} \mathrm{H}$ NMR spectroscopic data was also acquired at the same time during each of the competition experiments. Examination of these ${ }^{1} \mathrm{H}$ NMR spectra revealed interesting changes in the chemical shifts of the resonances arising from the trans protons (Figure 5a) on the isoxazolidine rings present in $\mathbf{T}^{\mathbf{p}}$ and $\mathbf{T}^{\mathbf{m}}$. These changes are visible most clearly in the competition kinetic experiment where the reaction mixture is instructed with $20 \mathrm{~mol} \%$ of $\mathbf{T}^{\mathbf{p}}$ (Figure 5a).

At the beginning of this reaction, replicator $\mathbf{T}^{\mathbf{p}}$, added at a concentration of $1 \mathrm{mM}$, is the dominant template in solution and no $\mathbf{T}^{\mathrm{m}}$ is present at the start of the reaction. In the presence of preformed $\mathbf{T}^{\mathbf{p}}$ template, $\mathbf{M}^{\mathbf{p}}, \mathbf{M}^{\mathbf{m}}$, and $\mathbf{N}$, are transformed quickly into both $\mathbf{T}^{\mathbf{p}}$ and $\mathbf{T}^{\mathbf{m}}$. As the concentration of $\mathbf{T}^{\mathbf{m}}$ increases in the reaction mixture over time, a significant change in the chemical shift of the resonance associated with the trans proton present in $\mathbf{T}^{\mathbf{p}}$ is observed. However, the resonance arising from replicator $\mathbf{T}^{\mathbf{m}}$ itself is apparently unperturbed. These observations are instructive, since they demonstrate strikingly the ability of replicators $\mathbf{T}^{\mathbf{p}}$ and $\mathbf{T}^{\mathbf{m}}$ to assemble into both homoduplexes $\left(\left[\mathbf{T}^{\mathrm{p}} \cdot \mathbf{T}^{\mathrm{p}}\right]\right.$ and $\left.\left[\mathbf{T}^{\mathrm{m}} \cdot \mathbf{T}^{\mathrm{m}}\right]\right)$ and the corresponding heteroduplex $\left(\left[\mathbf{T}^{\mathrm{p}} \cdot \mathbf{T}^{\mathrm{m}}\right]\right)$. The presence of

a single resonance for each template indicates that the exchange between these species is fast on the ${ }^{1} \mathrm{H}$ 
NMR chemical shift timescale. For each replicator, the observed chemical shift depends on the mole fraction of the replicator bound within its homoduplex and the heteroduplex.
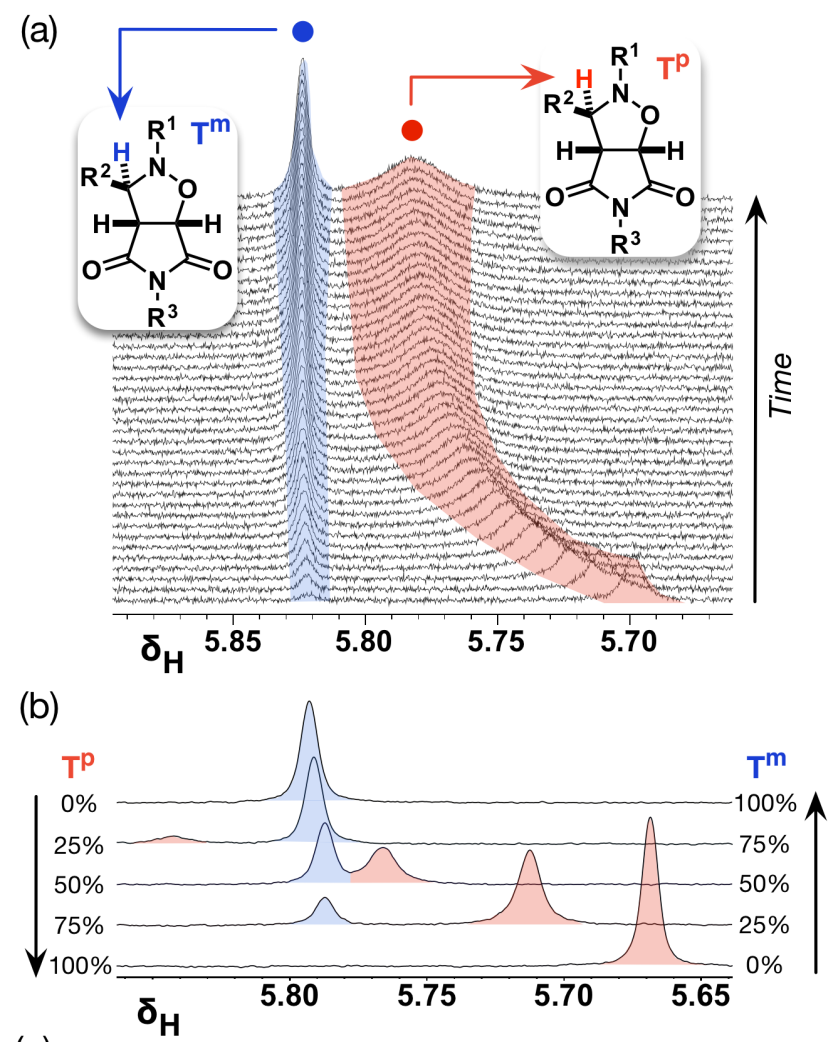

(c)

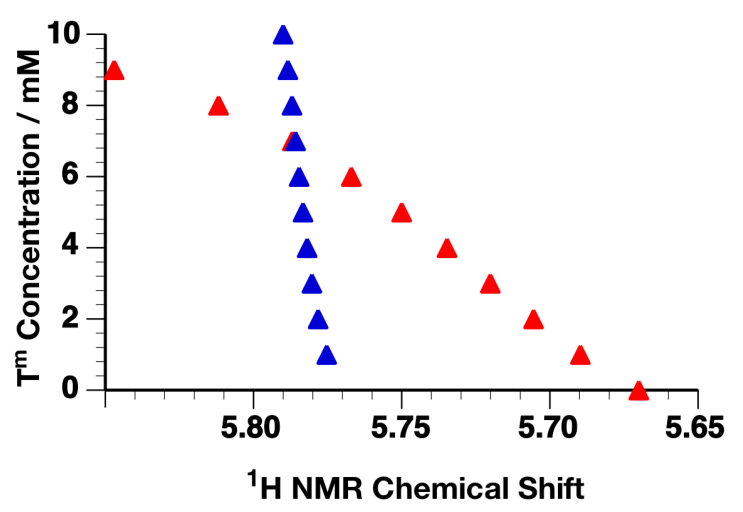

$\delta_{\mathbf{T}^{\mathrm{p}}}(\mathrm{obs})=f_{\left[\mathbf{T}^{\mathrm{p}} \cdot \mathbf{T}^{\mathrm{p}}\right]} \cdot \delta_{\left[\mathbf{T}^{\mathrm{p}} \cdot \mathbf{T}^{\mathrm{p}}\right]}+f_{\left[\mathbf{T}^{\mathrm{p}} \cdot \mathbf{T}^{\mathrm{m}}\right]} \cdot \delta_{\left[\mathbf{T}^{\mathrm{p}} \cdot \mathbf{T}^{\mathrm{m}}\right]}$
$\delta_{\mathbf{T}^{\mathrm{m}}}(\mathrm{obs})=f_{\left[\mathbf{T}^{\mathrm{m}} \cdot \mathbf{T}^{\mathrm{m}}\right]} \cdot \delta_{\left[\mathbf{T}^{\mathrm{m}} \cdot \mathbf{T}^{\mathrm{m}}\right]}+f_{\left[\mathbf{T}^{\mathrm{p}} \cdot \mathbf{T}^{\mathrm{m}}\right]} \cdot \delta_{\left[\mathbf{T}^{\mathrm{p}} \cdot \mathbf{T}^{\mathrm{m}}\right]}$

Figure 5. $\quad$ (a) Arrayed partial $499.9 \mathrm{MHz}{ }^{1} \mathrm{H}$ NMR spectra showing the changes in the chemical shifts of the resonances associated with the trans protons on the isoxazolidine ring of $\mathbf{T}^{\mathbf{p}}$ (red) and $\mathbf{T}^{\mathbf{m}}$ (blue) replicators formed within a competition experiment instructed with $\mathbf{T}^{\mathbf{p}}$ template $\left(\left[\mathbf{M}^{\mathbf{p}}\right]=\left[\mathbf{M}^{\mathbf{m}}\right]=[\mathbf{N}]=5 \mathrm{mM},\left[\right.\right.$ trans $\left.\left.-\mathbf{T}^{\mathbf{p}}\right]=1 \mathrm{mM}, \mathrm{CDCl}_{3}, 5^{\circ} \mathrm{C}\right)$ over time. (b) Overlay of partial $400.1 \mathrm{MHz}{ }^{1} \mathrm{H}$ NMR spectra (RT) showing the trans resonances belonging to the $\mathbf{T}^{\mathbf{p}}$ and $\mathbf{T}^{\mathbf{m}}$ cycloadducts. The chemical shift changes for these trans products were examined at five different conditions: starting with $\mathbf{T}^{\mathbf{p}}$ only and progressively increasing the content of $\mathbf{T}^{\mathbf{m}}$ to $100 \%$ (combined concentration of $\mathbf{T}^{\mathbf{p}}$ and $\mathbf{T}^{\mathbf{m}}=10 \mathrm{mM}$ ). (c) Simulated changes in the chemical shifts of the isoxazolidine trans proton (see (a)) in trans- $\mathbf{T}^{\mathbf{p}}$ (red triangles) and in trans$\mathbf{T}^{\mathbf{m}}$ (blue triangles), arising as a result of the distribution of these products in homo and heteroduplexes. Data are derived from simulations run using Gepasi 3 (Ref. 22), using the duplex association constants determined through fitting of kinetic data and estimated/determined chemical shifts for each duplex in the system. 
In order to develop a better understanding of these chemical shift changes, we examined the ${ }^{1} \mathrm{H}$ NMR spectra (Figure $5 \mathbf{b}$ ) recorded on five solutions of $\mathbf{T}^{\mathbf{p}}$ and $\mathbf{T}^{\mathbf{m}}$ at a combined concentration of 10 $\mathrm{mM}$ in $\mathrm{CDCl}_{3}$, starting with a composition of $100 \% \mathbf{T}^{\mathbf{p}}$ and increasing the fraction of $\mathbf{T}^{\mathbf{m}}$ progressively from $0 \%$ to $25 \%, 50 \%, 75 \%$, and, finally, $100 \%$. Each mixture was analyzed by $500.1 \mathrm{MHz}{ }^{1} \mathrm{H}$ NMR spectroscopy (Figure 5b, for the corresponding ${ }^{19} \mathrm{~F}\left\{{ }^{1} \mathrm{H}\right\}$ NMR spectra, see Figure S9). These five experiments allowed the changes in the chemical shifts arising from the resonances of both replicators to be examined under conditions where only homoduplex $\left[\mathbf{T}^{\mathbf{p}} \cdot \mathbf{T}^{\mathbf{p}}\right]$ or homoduplex $\left[\mathbf{T}^{\mathbf{m}} \cdot \mathbf{T}^{\mathbf{m}}\right]$ are present, as well as the three intermediate conditions where both homo- and heteroduplexes are present together. Analysis of the chemical shift changes observed in the isoxazolidine ring protons colored red and blue (Figure 5) as a function of the $\mathbf{T}^{\mathbf{p}}$ and $\mathbf{T}^{\mathbf{m}}$ composition revealed a markedly different behavior for replicator $\mathbf{T}^{\mathbf{p}}$ relative to $\mathbf{T}^{\mathbf{m}}$. While the chemical shift of the resonance arising from $\mathbf{T}^{\mathbf{m}}$ varied very little across the four different compositions examined $\left(25 \% \mathbf{T}^{\mathbf{m}} \rightarrow 100 \% \mathbf{T}^{\mathbf{m}}\right)$, the chemical shift of the resonance arising from $\mathbf{T}^{\mathbf{p}}$ exhibited a dramatic downfield shift $(>0.2 \mathrm{ppm}$, Figure $\mathbf{5 b})$ as the fraction of $\mathbf{T}^{\mathbf{m}}$ in the solution increases.

We modelled the steady state distributions of $\mathbf{T}^{\mathbf{p}}$ and $\mathbf{T}^{\mathbf{m}}$ within the various product duplexes present in solution and, consequently, the expected chemical shift for the resonances arising from the isoxazolidine protons present in $\mathbf{T}^{\mathbf{p}}$ and $\mathbf{T}^{\mathbf{m}}$ (colored red and blue in Figure 5c) by combining the data in Figure 5b with the corresponding association constants for the homo- and heteroduplexes determined earlier through kinetic fitting. Figure 5c shows the calculated chemical shifts for the appropriate proton resonances in $\mathbf{T}^{\mathbf{p}}$ and $\mathbf{T}^{\mathbf{m}}$ at nine different concentration ratios. Comparison of these calculated chemical shifts to the experimentally determined ${ }^{1} \mathrm{H}$ NMR data shows a clear qualitative agreement. The high stability of $\left[\mathbf{T}^{\mathbf{m}} \cdot \mathbf{T}^{\mathbf{m}}\right]$ is reflected by the fact that the chemical shift of the isoxazolidine proton associated with this product remains virtually unchanged throughout the experiments. Since $\left[\mathbf{T}^{\mathbf{p}} \cdot \mathbf{T}^{\mathbf{p}}\right]$ is the least stable duplex, as the concentration of $\mathbf{T}^{\mathbf{m}}$ is increased, the distribution of $\mathbf{T}^{\mathbf{p}}$ is shifted towards the more stable $\left[\mathbf{T}^{\mathbf{p}} \cdot \mathbf{T}^{\mathbf{m}}\right]$ duplex, evidenced by the $0.2 \mathrm{ppm}$ downfield shift in the resonance arising from trans- $\mathbf{T}^{\mathbf{p}}$. The analysis of the behavior of the $\left[\mathbf{T}^{\mathbf{p}} \cdot \mathbf{T}^{\mathbf{m}}\right]$ heteroduplex demonstrated that the differences in duplex stabilities have a dramatic influence over not only the auto- and crosscatalytic efficiencies of the two replicators, but also the chemical shifts of the resonances associated with these templates. In this case, we were able to use the thermodynamic parameters derived though kinetic fitting to successfully relate the variation in duplex and heteroduplex stabilities to the variation in the chemical shifts observed for templates $\mathbf{T}^{\mathbf{p}}$ and $\mathbf{T}^{\mathbf{m}}$ within the highly interconnected network. Additionally, these differences in the strengths of recognition processes that underlie the formation of replicators $\mathbf{T}^{\mathbf{p}}$ and $\mathbf{T}^{\mathbf{m}}$ and the associated complexes/duplexes also help to 
determine the outcome of competition in this network of replicators $-\mathbf{T}^{\mathbf{m}}$ is not only able to exploit $\mathbf{T}^{\mathbf{p}}$ for its formation, it is also capable of sequestering $\mathbf{T}^{\mathbf{p}}$ in a duplex that decreases its availability in solution and, as a result, the efficiency of the autocatalytic pathway leading to the formation of $\mathbf{T}^{\mathbf{p}}$.

\section{What governs the outcome of competition in $T^{\mathrm{p}}-T^{\mathrm{m}}$ network?}

The comprehensive set of kinetic experiments described here allowed us to examine each catalytic pathway in isolation and within a number of competition scenarios. The observed results demonstrate clearly that the absence of one crosscatalytic relationship ( $\mathbf{T}^{\mathrm{m}}$ is not a catalyst for the formation of $\mathbf{T}^{\mathbf{p}}$ ) has a significant influence on the behavior of the replicator network in a situation where $\mathbf{T}^{\mathbf{m}}$ and $\mathbf{T}^{\mathbf{p}}$ have to compete for a shared building block. The kinetic fitting demonstrates that there are significant differences between the two replicators in terms of the duplex association constants and unimolecular rate constants for the reactions that take place on templates. The origin of the disparity in the crosscatalytic efficiencies of $\mathbf{T}^{\mathbf{m}}$ and $\mathbf{T}^{\mathbf{p}}$, identified by our kinetic simulations and fitting, must lie in subtle differences in the stabilities and structures of the ternary complexes, $\left[\mathbf{N} \cdot \mathbf{M}^{\mathbf{p}} \cdot \mathbf{T}^{\mathrm{m}}\right]$ and $\left[\mathbf{N} \cdot \mathbf{M}^{\mathrm{m}} \cdot \mathbf{T}^{\mathrm{p}}\right]$, and the transition states accessed from these complexes. In order to gain a better understanding of these processes, we undertook a series of density functional theory calculations that examined the structures of the ternary complexes $\left[\mathbf{N} \cdot \mathbf{M}^{\mathbf{p}} \cdot \mathbf{T}^{\mathrm{m}}\right]$ and $\left[\mathbf{N} \cdot \mathbf{M}^{\mathrm{m}} \cdot \mathbf{T}^{\mathrm{p}}\right]$, the heteroduplex $\left[\mathbf{T}^{\mathbf{p}} \cdot \mathbf{T}^{\mathrm{m}}\right]$, and the transition states (TSs) that connect these complexes. All of these calculations were performed at the $\omega \mathrm{B} 97 \mathrm{X} / \mathrm{def}$-SVP level of theory using a continuum solvation model (PCM) for chloroform (see Supporting Information for details). In addition, we compared the transition state structures calculated for the template-directed reactions with that computed for the prototypical 1,3dipolar cycloaddition of diphenylnitrone to $N$-phenyl maleimide. Although the relative stereochemistry of the forming cycloadduct is controlled very well in favor of the trans diastereoisomer, the absolute stereochemical relationships between the templates are more complex. The template-directed reactions can proceed by one of two pathways. The stereochemistry of the newly formed replicator can match that of the template, for example, $R S R-\mathbf{T}^{\mathbf{p}} \rightarrow R S R-\mathbf{T}^{\mathbf{m}}$ - we will refer to this pathway as "matched". Alternatively, the stereochemistry of the newly formed replicator can be mismatched compared to that of the template, for example, $R S R-\mathbf{T}^{\mathbf{p}} \rightarrow S R S-\mathbf{T}^{\mathbf{m}}$ - we will refer to this pathway as "mismatched". 


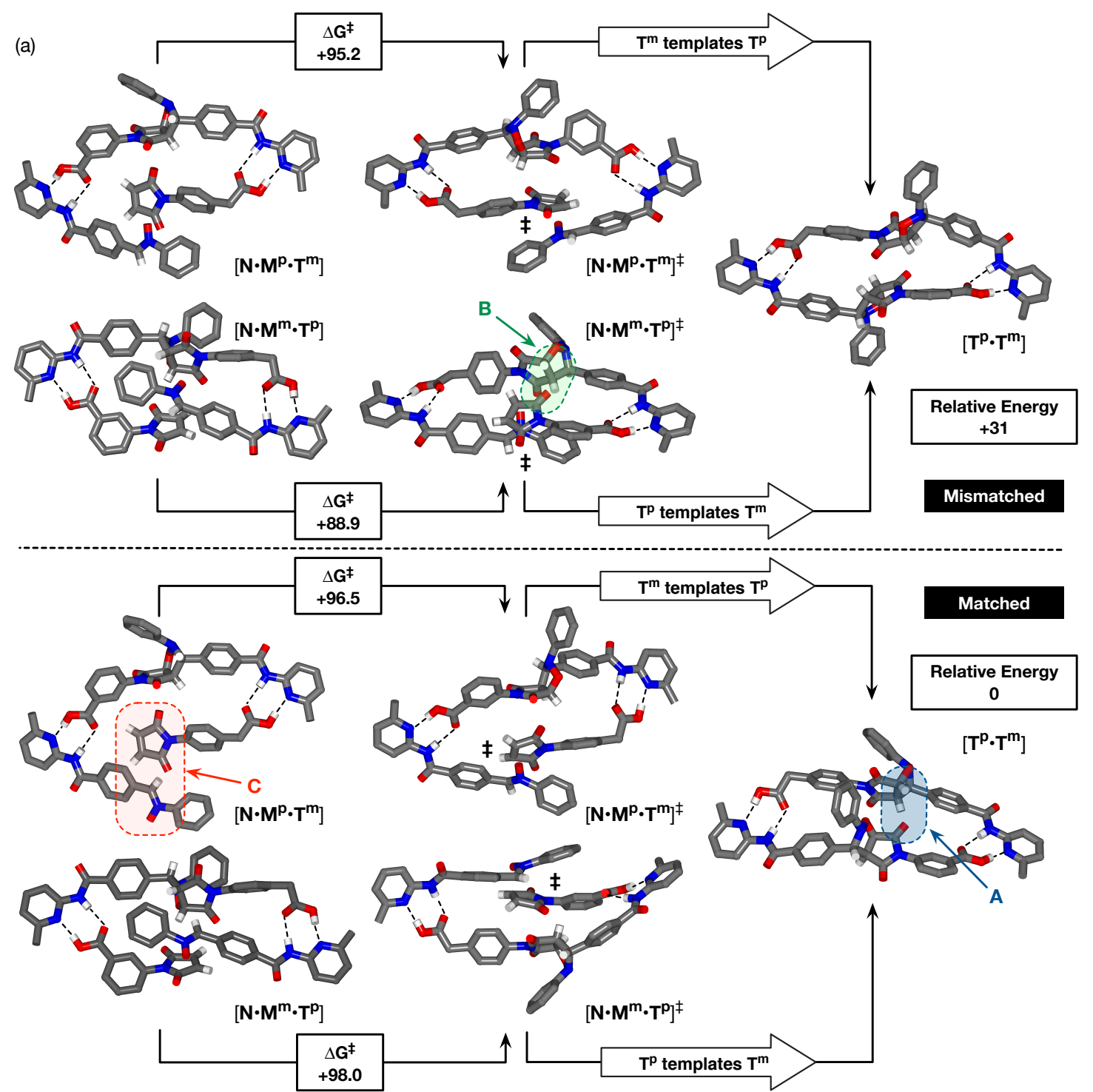

(b)

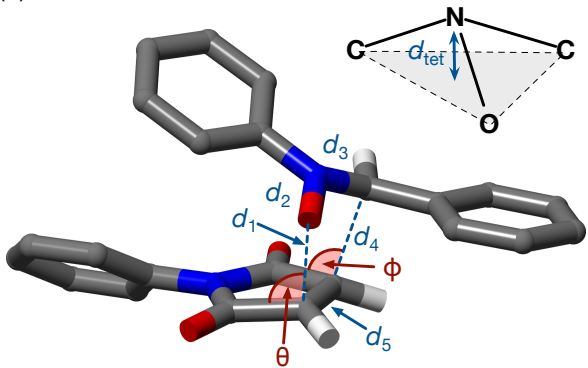

\begin{tabular}{ccccccccc}
\hline Comparison & $d_{1}$ & $d_{2}$ & $d_{3}$ & $d_{4}$ & $d_{5}$ & $d_{\text {tet }}$ & $\theta$ & $\phi$ \\
\hline Reagents & - & 1.264 & 1.309 & - & 1.332 & 0.015 & - & - \\
Parent TS & 2.086 & 1.279 & 1.345 & 2.140 & 1.386 & 0.141 & 96.95 & 103.09 \\
\hline Matched & $d_{1}$ & $d_{2}$ & $d_{3}$ & $d_{4}$ & $d_{5}$ & $d_{\text {tet }}$ & $\theta$ & $\phi$ \\
\hline$\left[\mathbf{N} \cdot \mathbf{M}^{\mathbf{m}} \cdot \mathbf{T}^{\mathbf{p}}\right]^{\ddagger}$ & 2.078 & 1.277 & 1.346 & 2.149 & 1.387 & 0.151 & 95.25 & 100.90 \\
{$\left[\mathbf{N} \cdot \mathbf{M}^{\mathbf{p}} \cdot \mathbf{T}^{\mathbf{m}}\right]^{\ddagger}$} & 2.106 & 1.277 & 1.348 & 2.106 & 1.387 & 0.149 & 95.26 & 106.18 \\
\hline $\mathbf{M} \mathbf{m} \mathbf{m a t c h e d}^{2}$ & $d_{1}$ & $d_{2}$ & $d_{3}$ & $d_{4}$ & $d_{5}$ & $d_{\text {tet }}$ & $\theta$ & $\phi$ \\
\hline $\left.\mathbf{N} \cdot \mathbf{M}^{\mathbf{m}} \cdot \mathbf{T}^{\mathbf{p}}\right]^{\ddagger}$ & 2.002 & 1.289 & 1.341 & 2.187 & 1.393 & 0.166 & 100.35 & 102.87 \\
{$\left[\mathbf{N} \cdot \mathbf{M}^{\mathbf{p}} \cdot \mathbf{T}^{\mathbf{m}}\right]^{\ddagger}$} & 2.096 & 1.277 & 1.346 & 2.128 & 1.386 & 0.148 & 96.95 & 104.37 \\
\hline
\end{tabular}

Figure 6. (a) Calculations reveal that the ternary complexes $\left[\mathbf{N} \cdot \mathbf{M}^{\mathbf{m}} \cdot \mathbf{T}^{\mathbf{p}}\right]$ and $\left[\mathbf{N} \cdot \mathbf{M}^{\mathbf{p}} \cdot \mathbf{T}^{\mathrm{m}}\right]$ can react to form the template duplex $\left[\mathbf{T}^{\mathbf{p}} \cdot \mathbf{T}^{\mathbf{m}}\right]$ through two sets of transition states - in which, the stereochemistries of the forming cycloadducts can be either matched or mismatched with respect to the replicator template-giving rise to four possible reaction pathways. Calculations were performed at the $\omega \mathrm{B} 97 \mathrm{X} / \mathrm{def} 2$-SVP level of theory using a continuum solvation model for chloroform. Energies are in $\mathrm{kJ} \mathrm{mol}^{-1}$. Hydrogen bonds are represented by dashed lines. The colored shaded areas indicated by letters are discussed in the main text. (b) Structural parameters describing the calculated structures $(\omega \mathrm{B} 97 \mathrm{X} / \mathrm{def} 2-\mathrm{SVP})$ for the four transition states accessed from either $\left[\mathbf{N} \cdot \mathbf{M}^{\mathrm{m}} \cdot \mathbf{T}^{\mathrm{p}}\right]$ or $\left[\mathbf{N} \cdot \mathbf{M}^{\mathrm{p}} \cdot \mathbf{T}^{\mathrm{m}}\right]$. Data for the corresponding parameters for the transition state located for the reaction of diphenylnitrone and $\mathrm{N}$-phenyl maleimide are provided for comparison. All distances are in $\AA$ and angles are in degrees. 
The consequence of these relationships is that heteroduplex $\left[\mathbf{T}^{\mathbf{p}} \cdot \mathbf{T}^{\mathbf{m}}\right]$, and the transition states leading to it, can exist either as a structure in which the stereochemistries of the templates are matched or as a structure in which the stereochemistries of the templates are mismatched. We computed the four possible pathways - matched and mismatched for both $\mathbf{T}^{\mathbf{p}} \rightarrow \mathbf{T}^{\mathbf{m}}$ and $\mathbf{T}^{\mathbf{m}} \rightarrow \mathbf{T}^{\mathbf{p}}$. The results of these calculations are summarized in Figure 6.

In the case of the template duplexes, the matched form of $\left[\mathbf{T}^{\mathbf{p}} \cdot \mathbf{T}^{\mathbf{m}}\right]$ is predicted to be around $30 \mathrm{~kJ} \mathrm{~mol}^{-1}$ more stable than the corresponding mismatched duplex. In part, this observation may be explained by the presence of stabilizing $\mathrm{C}-\mathrm{H} \bullet \bullet \mathrm{O}$ interactions along the spine of the template (marked A and highlighted in blue in Figure 6a) that are present in the matched duplex, but not in the mismatched one. Additionally, there are some distortions in the conformations of the fused bicyclic cycloadducts present in the mismatched $\left[\mathbf{T}^{\mathbf{p}} \cdot \mathbf{T}^{\mathbf{m}}\right]$ duplex that are required in order to maintain the four hydrogen bonds connecting the two templates.

Comparison of the transition states that were located for the four available pathways reveals that one structure-mismatched $\mathbf{T}^{\mathbf{p}} \rightarrow \mathbf{T}^{\mathbf{m}}$ (Figure 6a) - is significantly lower in energy than the other three. This observation is consistent with the experimental results indicating that $\mathbf{T}^{\mathbf{p}}$ can act as a catalyst for the formation of $\mathbf{T}^{\mathbf{m}}$, but $\mathbf{T}^{\mathbf{m}}$ is not a particularly efficient catalyst for the formation of $\mathbf{T}^{\mathbf{p}}$. Comparison of the transition state structures with that of the parent cycloaddition between diphenylnitrone and $N$-phenyl maleimide (Figure 6b) reveals that the mismatched transition state $\left[\mathbf{N} \cdot \mathbf{M}^{\mathbf{m}} \cdot \mathbf{T}^{\mathbf{p}}\right]^{\ddagger}$ has a geometry that differs considerably from the other three and from the parent. In this transition state, $\mathrm{C}-\mathrm{O}$ bond formation is more advanced $(\mathrm{C} \cdot \bullet \cdot \mathrm{O}=2.002 \AA$ vs. $2.086 \AA$ in parent TS) and $\mathrm{C}-\mathrm{C}$ bond formation is much less advanced $(\mathrm{C} \cdot \bullet \mathrm{C}=2.187 \AA$ vs. $2.146 \AA$ in parent $\mathrm{TS})$ than in any of the other three transition states accessible from the ternary complexes. This distortion suggests a transition state that may be slightly more polar $^{23}$ that the other three and may be stabilized by a series of $\mathrm{C}-\mathrm{H} \bullet \bullet \mathrm{O}$ interactions present along the spine of the template (marked $\mathbf{B}$ and highlighted in green in Figure 6a).

Whilst the structures of the transition states and the duplexes have limited conformational freedom as they adopt co-conformations that maintain four hydrogen bonds, the ternary complexes are much less restricted in a conformational sense. Bruice and Lightstone have shown ${ }^{24}$ that the rates of intramolecular reactions can be related to the fraction of low energy conformations that are present as near-attack conformations (NACs). Previously, we have applied ${ }^{25}$ this type of analysis successfully to a recognition-mediated pseudointramolecular cycloaddition reaction. Therefore, when considering these structures, we restricted our examination to structures that could be categorized loosely as NACs, i.e., we examined the structures in which the termini of the $4 \pi$ and $2 \pi$ components of the cycloaddition were 
in closest proximity. Interestingly, in the lowest energy structure located for each ternary complex, there is a striking difference between the distances that separate the reactive termini of the $4 \pi$ and $2 \pi$ components $(\mathrm{C} \bullet \bullet \mathrm{O}$ and $\mathrm{C} \bullet \bullet \mathrm{C})$ depending on the identity of the replicator that is acting as the template.

In the ternary complex $\left[\mathbf{N} \cdot \mathbf{M}^{\mathbf{p}} \cdot \mathbf{T}^{\mathbf{m}}\right]$, where $\mathbf{T}^{\mathbf{m}}$ is templating the formation of $\mathbf{T}^{\mathbf{p}}$, all of the $\mathrm{C} \bullet \bullet \mathrm{O}$ and $\mathrm{C} \bullet \cdot \mathrm{C}$ distances are above $4 \AA$ and, in the case of matched $\left[\mathbf{N} \cdot \mathbf{M}^{\mathbf{p}} \cdot \mathbf{T}^{\mathbf{m}}\right]$, over $5 \AA$ (marked $\mathbf{C}$ and highlighted in red in Figure 6a). These large distances suggest that the low energy coconformations of $\left[\mathbf{N} \cdot \mathbf{M}^{\mathbf{p}} \cdot \mathbf{T}^{\mathbf{m}}\right]$ are unlikely to contain a high fraction of NACs. This observation is consistent with lower efficiency of this ternary complex determined experimentally. By contrast, in $\left[\mathbf{N} \cdot \mathbf{M}^{\mathbf{m}} \cdot \mathbf{T}^{\mathbf{p}}\right]$, where $\mathbf{T}^{\mathbf{p}}$ is templating the formation of $\mathbf{T}^{\mathbf{m}}$, all of the $\mathrm{C} \cdot \bullet \mathrm{O}$ and $\mathrm{C} \cdot \bullet \mathrm{C}$ distances are below $4 \AA$ and in the case of the mismatched ternary complex, these distances are both below $3.40 \AA$. These very short distances suggest that the low energy co-conformations of mismatched $\left[\mathbf{N} \cdot \mathbf{M}^{\mathbf{p}} \cdot \mathbf{T}^{\mathbf{m}}\right]$ are likely to contain a high fraction of NACs and this observation is consistent with this ternary complex accessing the lowest energy transition state.

These calculations also offer a window into a more complex world that is currently beyond the reach of our experiments, in which the stereochemical relationships between replicators can play an important role in determining the outcome of competition ${ }^{8 b, 8 e, 26}$ between the replicators. Going forward, these results demand that, in order to maximize the efficiency of a template-directed process, it will be necessary to consider the detailed relationship between individual molecular structures and their co-conformations within complexes.

\section{Conclusions}

Small networks of minimal replicators may serve ${ }^{27}$ as simple models for primitive metabolic pathways in that the population of an individual replicator within these networks can be manipulated by exploiting the autocatalytic properties of the replicating template in order to specifically upregulate the rate of formation of that template. In this work, we describe the experimental implementation of such a network constructed from three simple building blocks - two maleimides $\left(\mathbf{M}^{\mathbf{m}}\right.$ and $\left.\mathbf{M}^{\mathbf{p}}\right)$ and a single nitrone $(\mathbf{N})$ - that react to create two synthetic replicators $\left(\mathbf{T}^{\mathbf{m}}\right.$ and $\left.\mathbf{T}^{\mathbf{p}}\right)$ that can template their own formation. Within this network, the two replicating templates compete for a common reagent, namely nitrone $\mathbf{N}$. In order to understand the system-level behavior of this network, it is important to characterize each replicator in isolation. In this case, our kinetic studies on $\mathbf{T}^{\mathbf{m}}$ and $\mathbf{T}^{\mathbf{p}}$ in isolation reveal that $\mathbf{T}^{\mathbf{p}}$ is the more efficient replicator of the pair. In isolation, $\mathbf{T}^{\mathbf{p}}$ benefits from a significantly higher effective molarity for the key cycloaddition step than $\mathbf{T}^{\mathbf{m}}$. Additionally, the $\left[\mathbf{T}^{\mathbf{p}} \cdot \mathbf{T}^{\mathbf{p}}\right]$ duplex is somewhat less stable than the $\left[\mathbf{T}^{\mathbf{m}} \cdot \mathbf{T}^{\mathbf{m}}\right]$ duplex, thereby ensuring that the concentration of catalytically 
active, monomeric $\mathbf{T}^{\mathbf{p}}$ is higher than in the corresponding reaction involving $\mathbf{T}^{\mathbf{m}}$. The abilities of both $\mathbf{T}^{\mathbf{p}}$ and $\mathbf{T}^{\mathbf{m}}$ to replicate are confirmed by their capacity to template their own formation as evidenced by experiments in which pre-formed template is added to a mixture of the nitrone and the appropriate maleimide at the start of the reaction. The structural similarity between $\mathbf{T}^{\mathbf{p}}$ and $\mathbf{T}^{\mathrm{m}}$ opens the possibility that a mutual crosscatalytic relationship may exist between these two templates. By exploring the response of reactions that form either $\mathbf{T}^{\mathbf{p}}$ or $\mathbf{T}^{\mathrm{m}}$ to the addition of the other template as an instruction, we established that, although $\mathbf{T}^{\mathbf{p}}$ can template the formation of $\mathbf{T}^{\mathbf{m}}, \mathbf{T}^{\mathbf{m}}$ does not catalyze the formation of $\mathbf{T}^{\mathbf{p}}$ effectively. The absence of reciprocity in the crosscatalytic relationship between $\mathbf{T}^{\mathbf{p}}$ and $\mathbf{T}^{\mathbf{m}}$ is critical to understanding the outcome of experiments in which $\mathbf{T}^{\mathbf{p}}$ and $\mathbf{T}^{\mathbf{m}}$ are placed in a competitive situation. Analysis of experiments in which $\mathbf{T}^{\mathbf{p}}$ and $\mathbf{T}^{\mathbf{m}}$ replicate in the same flask reveal the apparently anomalous observation that the replicator that is less efficient in isolation $\left(\mathbf{T}^{\mathbf{m}}\right)$ becomes the dominant species in the complete network. This observation is a direct result of the presence of the nonreciprocal crosscatalytic interaction between $\mathbf{T}^{\mathbf{p}}$ and $\mathbf{T}^{\mathbf{m}}$, which allows $\mathbf{T}^{\mathbf{m}}$ to exploit $\mathbf{T}^{\mathbf{p}}$ for its formation but not vice versa. The system-level outcome is also driven by the subtle interplay of the recognition and reaction processes. Replicator $\mathbf{T}^{\mathrm{m}}$ forms more stable complexes and duplexes, which allows it to reduce the replication efficiency of $\mathbf{T}^{\mathrm{p}}$ by sequestering it within the $\left[\mathbf{T}^{\mathbf{p}} \cdot \mathbf{T}^{\mathrm{m}}\right.$ ] heteroduplex that is more stable than the $\left[\mathbf{T}^{\mathrm{p}} \cdot \mathbf{T}^{\mathrm{p}}\right]$ homoduplex. However, our attempts to direct the competition between the replicators using preformed templates under the well-stirred batch reactor conditions employed here always result in the erosion of the imbalance between the two replicators generated at early time points. This effect is a direct result of the exhaustion of building blocks that limits the efficiency of replication processes, thereby preventing the initially dominant replicator from enhancing its advantage. This observation illustrates clearly that the ability of one replicator to dominate within this network depends not only on its catalytic relationship with the other replicator in the network but also their reaction environment. The current work represents a firm foundation for the expansion of the study of replicator networks under conditions where dynamic processes or diffusion contribute to the outcome of replicator competition-i.e., reaction conditions where replication processes can operate with increased efficiency. These studies are currently underway in our laboratory. 


\section{Acknowledgements}

The financial support for this work was provided by the University of St Andrews and the Engineering and Physical Sciences Research Council (Grant EP/K503162/1).

\section{Supporting information:}

Supporting information is available free of charge at:

General experimental procedures; synthetic procedures and compound characterization; details of kinetic analyses, fitting (including fitted kinetic profiles), and simulations, and details of DFT calculations.

\section{Notes and References}

(1) (a) Newmann, M. E. J. SIAM Rev. 2003, 45, 167. (b) Barabási, A.-L. Rev. Mod. Phys. 2002, 74, 1. (c) Strogatz, S. H. Nature 2001, 410, 268.

(2) (a) Rieckmann, J. C.; Geiger, R.; Hornurg, D.; Wolf, T.; Kveler, K.; Jarossay, D.; Sallusto, F.; Shen-Orr, S. S.; Lanzavecchia, A.; Mann, M.; Meissner, F. Nat. Immunol. 2017, 18, 583. (b) Boccaletti, S.; Latora, V.; Moreno, Y.; Chavez, M.; Hwang, D. U. Phys. Rep. 2006, 424 (4-5), 175. (c) Barabási, A.-L.; Oltvai, Z. N. Nat. Rev. Genet. 2004, 5, 101. (d) Jeong, H.; Tombor, B.; Albert, R.; Oltvai, Z. N.; Barabási, A.-L. Nature 2000, 407, 651.

(3) (a) Mitchell, M. Complexity: A Guided Tour; Oxford University Press: New York, 2009. (b) Watts, D. J. Small Worlds: The Dynamics of Networks between Order and Randomness; Princeton University Press: New Jersey, 2003. (c) Barabási, A.-L. Linked: The New Science of Networks; Perseus Book Group: New York, 2002.

(4) Kauffman, S. A. At Home in the Universe: The Search for the Laws of Self-Organization and Complexity; Oxford University Press Inc.: New York, 1995.

(5) (a) Ashkenasy, G.; Hermans, T. M.; Otto, S.; Taylor, A. F. Chem. Soc. Rev. 2017, 46, 2543. (b) De la Escosura, A.; Briones, C.; Ruiz-Mirazo, K. J. Theor. Biol. 2015, 381, 11. (c) Mattia, E.; Otto, S. Nat. Nanotechnol. 2015, 10, 111. (d) Ruiz-Mirazo, K.; Briones, C.; de la Escosura, A. Chem. Rev. 2014, 114, 285. (e) von Kiedrowski, G.; Otto, S.; Herdewijn, P. J. Syst. Chem. 2010, 1, 1. (f) Peyralans, J. J.; Otto, S. Curr. Opin. Chem. Biol. 2009, 13, 705. (g) Stankiewicz, J.; Eckardt, L. H. Angew. Chem. Int. Ed. 2006, 45, 342.

(6) (a) Plöger, T. A.; von Kiedrowski, G. Org. Biomol. Chem. 2014, 12, 6908. (b) Paul, N.; Joyce, G. F. Proc. Natl. Acad. Sci. USA 2002, 99, 12733. (c) Luther, A.; Brandsch, R.; von Kiedrowski, G. Nature 1998, 396, 245. (d) Sievers, D.; von Kiedrowski, G. Nature 1994, 369, 221. (e) von Kiedrowski, G.; Wlotzka, B.; Helbing, J.; Matzen, M.; Jordan, S. Angew. Chem. Int. Ed. Engl. 1991, 30, 423. (f) von Kiedrowski, G. Angew. Chem. Int. Ed. Engl. 1986, 25, 932.

(7) (a) Colomb-Delsuc, M.; Mattia, E.; Sadownik, J. W.; Otto, S. Nat. Commun. 2015, 6, 7427. (b) Carnall, J. M. A.; Waudby, C. A.; Belenguer, A. M.; Stuart, M. C. A.; Peyralans, J. J.-P.; Otto, S. Science 2010, 327, 1502. (c) Li, X.; Chmielewski, J. J. Am. Chem. Soc. 2003, 125, 11820. (d) Issac, R.; Chmielewski, J. J. Am. Chem. Soc. 2002, 124, 6808. (e) Yao, S.; Ghosh, I.; Zutshi, R.; Chmielewski, J. Angew. Chem. Int. Ed. Engl. 1998, 37, 478. (f) Severin, K.; Lee, D. H.; Kennan, A. J.; Ghadiri, M. R. Nature 1997, 389, 706. (g) Yao, S.; Ghosh, I.; Zutshi, R.; Chmielewski, J. J. Am. Chem. Soc. 1997, 119, 10559. (h) Lee, D. H.; Granja, J. R.; Martinez, J. A.; Severin, K.; Ghadri, M. R. Nature 1996, 382, 525. 
(8) (a) Bottero, I.; Huck, J.; Kosikova, T.; Philp, D. J. Am. Chem. Soc. 2016, 138, 6723. (b)

Dieckmann, A.; Beniken, S.; Lorenz, C. D.; Doltsinis, N. D.; von Kiedrowski, G. Chem. Eur. J. 2011, 17, 468. (c) Kassianidis, E.; Philp, D. Angew. Chem. Int. Ed. 2006, 45, 6344. (d) Pearson, R. J.; Kassianidis, E.; Slawin, A. M. Z.; Philp, D. Chem. Eur. J. 2006, 12, 6829. (e) Kindermann, M.; Stahl, I.; Reimold, M.; Pankau, W. M.; von Kiedrowski, G. Angew. Chem. Int. Ed. 2005, 44, 6750. (f) Pearson, R. J.; Kassianidis, E.; Slawin, A. M. Z.; Philp, D. Org. Biomol. Chem. 2004, 2, 3434. (g) Quayle, J. M.; Slawin, A. M. .; Philp, D. Tetrahedron Lett. 2002, 43, 7229. (h)

Wang, B.; Sutherland, I. O. Chem. Commun. 1997, 1495. (i) Rotello, V.; Hong, J.-I.; Rebek, Jr., J. J. Am. Chem. Soc. 1991, 113, 9422. (j) Tjivikua, T.; Ballester, P.; Rebek, Jr., J. J. Am. Chem. Soc. 1990, 112, 1249.

(9) Severin, K.; Lee, D. H.; Martinez, J. A.; Vieth, M.; Ghadiri, M. R. Angew. Chem. Int. Ed. Engl. 1998, 37, 126.

(10) Saghatelian, A.; Yokobayashi, Y.; Soltani, K.; Ghadiri, M. R. Nature 2001, 409, 797.

(11) (a) Ashkenasy, G.; Dadon, Z.; Alesebi, S.; Wagner, N.; Ashkenasy, N. Isr. J. Chem. 2011, 51, 106. (b) Allen, V. C.; Robertson, C. C.; Turega, S. M.; Philp, D. Org. Lett. 2010, 12, 1920. (c) Ashkenasy, G.; Ghadiri, M. R. J. Am. Chem. Soc. 2004, 126, 11140.

(12) (a) Sadownik, J. W.; Mattia, E.; Nowak, P.; Otto, S. Nat. Chem. 2016, 8, 264. (b) Dadon, Z.; Wagner, N.; Ashkenasy, G. Angew. Chem. Int. Ed. 2008, 47, 6128. (c) Ashkenasy, G.; Jagasia, R.; Yadav, M.; Ghadiri, M. R. Proc. Natl. Acad. Sci. USA 2004, 101, 10872. (d) Yao, S.; Ghosh, I.; Zutshi, R.; Chmielewski, J. Nature 1998, 396, 447. (e) Lee, D. H.; Severin, K.; Yokobayashi, Y.; Ghadiri, M. R. Nature 1997, 390, 591.

(13) (a) Kim, D.-E.; Joyce, G. F. Chem. Biol. 2004, 11, 1505. (b) Sievers, D.; Von Kiedrowski, G. Chem. Eur. J. 1998, 4, 629.

(14) (a) Kosikova, T.; Hassan, N. I.; Cordes, D. B.; Slawin, A. M. Z.; Philp, D. J. Am. Chem. Soc. 2015, 137, 16074. (b) Kassianidis, E.; Pearson, R. J.; Wood, E. A.; Philp, D. Faraday Discuss. 2010, 145, 235. (c) Sadownik, J. W.; Philp, D. Angew. Chem. Int. Ed. 2008, 47, 9965. (d) Xu, S.; Giuseppone, N. J. Am. Chem. Soc. 2008, 130, 1826.

(15) (a) Bissette, A. J.; Fletcher, S. P. Angew. Chem. Int. Ed. 2013, 52, 12800. (b) Philp, D.; Huck, J. Supramolecular Chemistry: From Molecules to Nanomaterials; John Wiley \& Sons, Ltd.: New York, 2012; Vol. 4, pp 1415. (c) Vidonne, A.; Philp, D. Eur. J. Org. Chem 2009, 2009, 593. (d) Patzke, V.; von Kiedrowski, G. ARKIVOC 2007, 46, 293. (e) von Kiedrowski, G. Bioorganic Chem. Front. 1993, 3, 113.

(16) The 1,3-dipolar cycloaddition reaction between a nitrone and a maleimide can give rise to two diastereoisomers, trans and cis. Only the trans diastereoisomers are capable of taking part in template-directed replication processes in the network of $\mathbf{T}^{\mathbf{p}}$ and $\mathbf{T}^{\mathbf{m}}$ replicators. For this reason, the notation for the trans cycloadducts capable of replication will generally omit the trans throughout this work (for example, trans $-\mathbf{T}^{\mathbf{p}}$ will be generally referred to as $\mathbf{T}^{\mathbf{p}}$, unless emphasis on the identity of the diastereoisomer is necessary). All preformed templates used in instructed experiments consisted exclusively of the trans diastereoisomer of the relevant replicator.

(17) This relationship presents a slight generalization, as whilst generally true, the increase in the strength of the recognition between two network components might also result in the formation of $[\mathbf{M} \cdot \mathbf{N}]$ type of complexes, which can reduce the efficiency of the autocatalytic pathway.

(18) The error values for the calculated \%EFs were determined using standard methods for calculation of normally distributed errors. These calculations employed the estimated value of concentration error of $\pm 0.02 \mathrm{mM}$ determined for all of the kinetic experiments described in this work (for details, see Supporting Information).

(19) Kinetic effective molarity provides a measure of the enhancement in the template-mediated pathway relative to the bimolecular pathway. $\mathrm{EM}_{\text {kinetic }}$ also tells us about the concentration at which the reaction would have to be performed in order for the bimolecular pathway to perform 
at the efficiency of the recognition-mediated pathway. For this reason, rate acceleration takes place even if $\mathrm{EM}_{\text {kinetic }}<1$, as long as the concentration at which the reaction is conducted is below the value of $\mathrm{EM}_{\text {kinetic. }}$

(20) Thermodynamic effective molarity provides information about the stability of the template duplex relative to the strength of the ternary complex.

(21) The values of template duplex association constants determined through kinetic fitting in this work were in the range of $\sim 17.9$ to $68.6 \times 10^{6} \mathrm{M}^{-1}$, i.e., a situation where the concentration of the catalytically active ternary complex will be in the $\mu \mathrm{M}$ range (see Ref. $8 \mathrm{c}$ for detailed analysis) under the conditions employed experimentally. Ideally, self-replicating systems would be examined at a concentration (C) that promotes the dissociation of the template duplex $\left([\mathrm{C}]_{\text {initial }}=1 / K_{\mathrm{a}}^{\text {Duplex }}\right)$. At such a concentration, however, the formation of the catalytically active ternary complex, which is driven by the considerably smaller $K_{\mathrm{a}}^{\text {Ind }}$ would be strongly disfavoured. The optimum conditions, therefore, need to balance these two competing influences.

(22) (a) Mendes, P. Comput. Applic. Biosci. 1993, 9, 563. (b) Mendes, P. Tends Biochem. Sci. 1997, 22,361 .

(23) Cowie, R. M.; Turega, S. M.; Philp, D. Org. Lett. 2006, 8, 5179.

(24) (a) Lightstone, F. C.; Bruice, T. C. J. Am. Chem. Soc. 1996, 118, 2595. (b) Bruice, T. C.; Lightstone, F. C. Acc. Chem. Res. 1999, 32, 127.

(25) Sinclair, A. J.; del Amo, V.; Philp, D. Org. Biomol. Chem. 2009, 7, 3308.

(26) (a) Ribó, J. M.; Crusats, J.; El-Hachemi, Z.; Moyano, A.; Hochberg, D. Chem. Sci. 2017, 8, 763. (b) Ribó, J. M.; Blanco , C.; Crusats , J.; El-Hachemi , Z.; Hochberg, D.; Moyano, A. Chem. Eur. J. 2014, 20, 17250. (c) Dieckmann, A.; Houk, K. N. Chem. Sci. 2013, 4, 3591.

(27) Shapiro, R. Q. Rev. Biol. 2006, 81, 105. 
For Table of Contents Only:

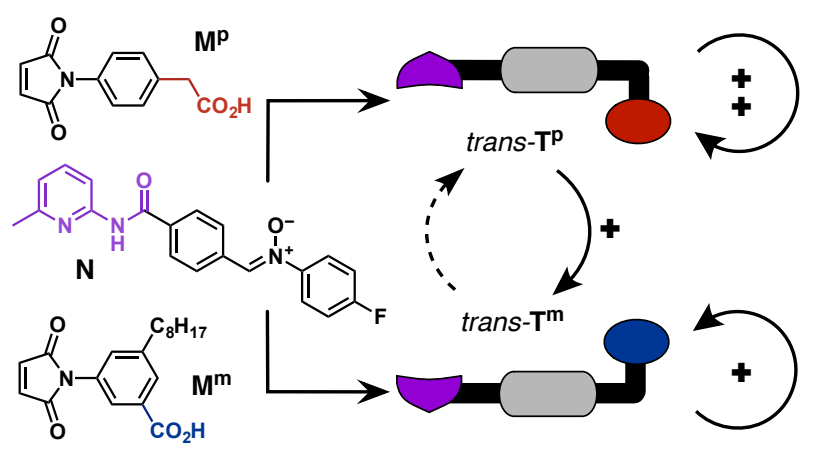

